NBER WORKING PAPER SERIES

\title{
EXCHANGE RATE, EQUITY PRICES AND CAPITAL FLOWS
}

\author{
Harald Hau \\ Hélène Rey \\ Working Paper 9398 \\ http://www.nber.org/papers/w9398
NATIONAL BUREAU OF ECONOMIC RESEARCH
1050 Massachusetts Avenue
Cambridge, MA 02138
December 2002

Deniz Igan provided outstanding research assistance. We thank Bernard Dumas, Pierre-Olivier Gourinchas, Olivier Jeanne, Arvind Krishnamurthy, Carol Osler and Michael Woodford for very useful dicussions and Richard Lyons, Michael Moore and Richard Portes for detailed comments on earlier drafts. Thanks also to participants in the 2002 NBER IFM summer institute and in seminars at Columbia, Georgetown, George Washington University and the IMF. We are both very grateful to the IMF Research Department for its warm hospitality and its stimulating environment while writing parts of this paper. Sergio Schmukler and Stijn Claessens provided the stock market capitalization data. This paper is part of a research network on 'The Analysis of International Capital Markets: Understanding Europe's Role in the Global Economy', funded by the European Commission under the Research Training Network Program (Contract No. HPRN(ECT(E 1999(E00067). The views expressed herein are those of the authors and not necessarily those of the National Bureau of Economic Research.

(C) 2002 by Harald Hau and Hélène Rey. All rights reserved. Short sections of text not to exceed two paragraphs, may be quoted without explicit permission provided that full credit including, (C) notice, is given to the source. 
Exchange Rate, Equity Prices and Capital Flows

Harald Hau and Hélène Rey

NBER Working Paper No. 9398

December 2002

JEL No. F3, F31, G1, G15

\begin{abstract}
$\underline{\text { ABSTRACT }}$
We develop an equilibrium model in which exchange rates, stock prices and capital flows are jointly determined under incomplete forex risk trading. Incomplete hedging of forex risk, documented for U.S. global mutual funds, has three important implications: 1) exchange rates are almost as volatile as equity prices when the forex liquidity supply is not infinitely price elastic; 2) higher returns in the home equity market relative to the foreign equity market are associated with a home currency depreciation; 3) net equity flows into the foreign market are positively correlated with a foreign currency appreciation. The model predictions are strongly supported at daily, monthly and quarterly frequencies for 17 OECD countries vis-à-vis the U.S. Moreover, correlations are strongest after 1990 and for countries with higher market capitalization relative to GDP, suggesting that the observed exchange rate dynamics is indeed related to equity market development.
\end{abstract}

Harald Hau

INSEAD

Department of Finance

Boulevard de Constance

77305 Fontainebleau Cedex

France

harald.hau@insead.edu
Hélène Rey

Department of Economics and Woodrow Wilson School Princeton University

Princeton, NJ 08544

and NBER

hrey@princeton.edu 


\section{Introduction}

The last 25 years have been characterized by a remarkable increase in international capital mobility. While gross cross-border transactions in bond and equity for the U.S. were equivalent to only 4 percent of GDP in 1975, this share increased to 100 percent in the early 1990s and has grown to 245 percent by 2000. Furthermore, a growing proportion of these capital flows consists of equity as opposed to bank loans or government bonds. ${ }^{1}$ The increasing size and equity content of current capital flows has not yet inspired a new financial market paradigm for exchange rate theory, in which exchange rates, equity market returns and capital flows are jointly determined.

Recently, positive exchange rate theory has advanced mostly outside the scope of traditional macroeconomic theory, plagued with its notoriously poor empirical performance (Meese and Rogoff (1983a, 1983b)) and with widespread pessimism about the explanatory power of macro variables in general. ${ }^{2}$ The empirical microstructure literature has examined the role of foreign exchange (forex) order flow defined as the difference between buy and sell orders. Evans and Lyons (2001a,b), Lyons (2001), Rime (2001), Killeen et al. (2001), and Hau et al. (2001) show that order flow from electronic trading systems have remarkably high correlation with contemporaneous exchange rate changes. These empirical results have been established both for inter-dealer order flow and for customer-dealer order flow. Since customer-dealer order flow in the foreign exchange market is at least partly determined by investors' desires for portfolio shifts, these results suggest an important linkage between exchange rate dynamics and investor behavior. The most comprehensive order flow data are owned by global custodians like State Street, which undertake a large proportion of global equity clearing. Such (proprietary) data have been analyzed by Froot et al. (2001) and Froot and Ramadorai (2002). The results show that the impact of investor order flow on the exchange rate is very persistent and peaks at horizons of about a month for major currencies. But the order flow exchange rate linkage has not yet been imbedded in a theoretical framework in which order flow is derived from international

\footnotetext{
${ }^{1}$ The London based research firm Cross Border Capital reports that during the period 1975-1984 bank loans accounted on average for $39.5 \%$ of total outflows from major industrialized countries $(60.3 \%$ of inflows), while equities accounted for only $9.5 \%$ of outflows (6.1\% of inflows). During the 1985-94 period these proportions were reversed. Bank loans accounted only for $8.3 \%$ of outflows ( $16.3 \%$ of inflows), while equities jumped to $35.9 \%$ of outflows (31.6\% of inflows). Similarly Lane and Milesi-Ferretti (2002) report that the ratio of foreign assets and liabilities to GDP has increased by $250 \%$ over the period 1984-2001. The same ratio computed only for equity and FDI has more than tripled over the same period. See also Frankel (1994) and Obstfeld and Taylor (2002).

${ }^{2}$ Frankel and Rose (1995) summarize the situation by saying that "... no model based on such standard fundamentals like money supplies, real income, interest rates, inflation rates, and current account balances will ever succeed in explaining or predicting a high percentage of the variation in the exchange rate, at least at short- or medium-term frequencies." More recently Devereux and Engel (2002) argue that one cannot match some stylized facts regarding exchange rate volatility and disconnect without adding ingredients such as noise traders to the standard models.
} 
investment behavior. There is still no model that bridges the gap between foreign exchange microstructure and macroeconomic fundamentals. To develop such a framework and explore its empirical implications is the main objective of this paper.

Our most important structural assumption concerns incomplete forex risk trading. In complete markets, exchange rate risk hedging is a free lunch (Perold and Schulman (1988), Karolyi and Stulz (2001)). Investors in the home country can simply swap and eliminate forex risk by trading it with foreign investors holding the reciprocal risk. Under full forex risk hedging, the domestic and international investment problems are alike unless we separate home and foreign investors by asymmetric information, different consumption opportunities or preferences. But the evidence on forex hedging strongly suggests that market completeness represents a highly counterfactual benchmark. We have survey evidence on mutual funds and other institutional investors which manage a large proportion of U.S. foreign equity investments. Their lower transaction costs and higher financial sophistication make them better candidates for forex risk trading compared to individual investors. Do they swap forex risk with their foreign counterparts? Levich et al. (1999) surveyed 298 U.S. institutional investors and found that more than 20 percent were not even permitted to hold derivative contracts in their investment portfolio. A further 25 percent of institutional investors were formally unconstrained, but did not trade in derivatives. The remaining 55 percent of institutional investors hedged only a minor proportion of their forex exposure. For the full sample, Levich et al. calculated that forex risk hedging concerned only 8 percent of the total foreign equity investment. ${ }^{3}$ Portfolio managers cited monitoring problems, lack of knowledge and public and regulatory perceptions as most important reasons for the restricted forex derivative use. The development of the derivative market notwithstanding, only a minor proportion of the total macroeconomic forex return risk seems to be separately traded and eliminated. The typical foreign equity investor holds currency return and foreign equity return risk as a bundle.

Exposure to exchange rate risk implies that the international investor generally cares about both the volatility of the exchange rate and the correlation structure of exchange rates and foreign equity returns. For example, higher exchange rate volatility tends to induce a home equity bias. On the other hand, a negative correlation between foreign exchange rate returns and foreign stock market returns reduces the return volatility in home currency terms and makes foreign investment more attractive. Portfolio choice therefore depends on exchange rate dynamics. But dynamic portfolio choice should simultaneously affect the exchange rate. Differences in stock market performances generate imbalances between the dividend income of home and foreign investors. Dynamic rebalancing of equity portfolios then initiates forex order flow, which in turn

\footnotetext{
${ }^{3}$ We also consulted market experts in two large U.S. custodians. Independent sources at both State Street Bank and Citibank estimated the notional forex hedge at less than 10 percent. This confirms the survey evidence.
} 
induces exchange rate movements.

We capture this interaction between optimal portfolio choice under market incompleteness and exchange rate dynamics in a simple model. Exchange rates, portfolio equity flows and equity returns are jointly and endogenously determined. For simplicity we assume that in each of the two countries of our world economy there is a constant risk-free interest rate and an exogenous stochastic dividend process for the equity market. Domestic and foreign investors are risk averse and maximize a simple trade-off between instantaneous trading profits and their variance. They can invest in both the domestic and foreign equity and bond markets. Dividend payments and equity purchases are undertaken in local currency. The exchange rate is determined under market clearing in the forex market where private investor order flows stemming from portfolio rebalancing and dividend repatriation meet a price-elastic forex supply of liquidity-providing financial institutions. The price-elastic forex supply simply captures the imperfect intertemporal forex speculation. ${ }^{4}$ It implies that order flow drives the exchange rate in accordance with the empirical findings in the recent microstructure literature.

The model we develop has testable implications regarding the relative volatilities of equity and exchange rate returns; correlations between stock index (excess) returns and exchange rate returns; and correlations between portfolio flows and exchange rate returns. We highlight here the three main empirical implications of our model:

1. Market incompleteness in combination with a low price elasticity of forex liquidity supply generates exchange rates which are almost as volatile as equity prices.

2. Higher returns in the home equity market (in local currency) relative to the foreign equity market are associated with a home currency depreciation.

3. Net equity flows into the foreign market are positively correlated with a foreign currency appreciation.

We confront these model predictions with the data. Ratios of exchange rate volatility to equity return volatility are generally smaller than one and in the range replicated by the model. Return correlations are examined with daily, monthly and quarterly stock index and exchange rate return data for 17 OECD countries. Strong statistical evidence is produced for a negative correlation between excess returns on foreign over U.S. equity and returns on the foreign currency as predicted by the model. Hence, both theory and evidence contradict the conventional wisdom that a strong equity market comes with a strong currency. We also highlight that these findings are produced at high statistical significance in contrast to the well-known failure of uncovered

\footnotetext{
${ }^{4}$ We refer to intertemporal forex trading as speculation and not as arbitrage because such strategies involve typically considerable risk taking.
} 
interest parity for the same set of countries. The evidence for the negative correlation between excess equity returns and exchange rate is strongest for the post-1990 period, when equity markets became more open. Cross sectionally, we find that the negative correlation is more pronounced for countries with the most developed equity markets. Finally, we also use monthly equity flow data on the same OECD countries to verify the portfolio flow implications. In accordance with the model, the pooled regressions reveal a positive correlation between equity flows into the foreign market and the appreciation of the foreign currency.

The following section discusses the literature before we describe the model in section 3 . In section 4 , we solve the model for two special cases, namely the case of financial autarky and full integration in a complete market setting. These two polar cases provide two benchmarks for the general case of financial integration under market incompleteness explored in section 5 . We summarize the most important testable implications in section 6 before confronting them with the data in section 7. Conclusions follow in section 8 .

\section{Literature Review}

It is useful to situate our analysis in the existing exchange rate literature. Our approach differs from previous studies in the following respects: (1) the emphasis on equity flows relative to the new open macroeconomics literature, (2) the financial market incompleteness assumption relative to the real business cycle literature, (3) the endogeneity of the order flows relative to the forex microstructure literature and (4) the explicit modeling of the exchange rate relative to the finance literature.

Macroeconomic theory has recently emphasized better microfoundations together with a more rigorous modelling of the dynamic current account. This approach is exemplified by Obstfeld and Rogoff (1995) and surveyed in Lane (2001). But international equity markets do not play an important role in this framework. While monopolistic profits occur in these models, they typically accrue entirely to domestic residents and therefore do not give rise to any equity flows. In the spirit of the traditional asset market approach to exchange rates (surveyed by Branson and Henderson (1985)), we link exchange rate movements and optimal foreign and domestic asset holdings. We obtain sharper testable implications for the correlation structure of forex returns, equity returns and equity flows.

Our analysis features incomplete forex risk trading as an important structural assumption. To the extent that real business cycle models allow for international asset trade, they typically examine the resulting exchange rate dynamics in a complete market setting. ${ }^{5}$ In this idealized

\footnotetext{
${ }^{5}$ Capital market incompleteness and the short sale constraint for foreign bonds set our model apart from the Lucas (1982) model and much of the stochastic dynamic general equilibrium literature. More recently, Duarte and Stockman (2001) develop an interesting general equilibrium model with incomplete asset markets and segmented
} 
setting all benefits from international exchange rate risk trading are realized. We argue that this assumption is at odds with current evidence on very low hedge ratios for foreign equity investment as discussed above. In our view the market trades equity fairly frictionlessly across borders, but fails to realize the full benefit of trading the associated forex risk. This market incompleteness is not related to the absence of the markets (forex derivatives exist), but rather to transaction and agency costs of using them.

This paper is inspired by the new empirical literature on the microstructure of the forex market. Order flow is identified as an important determinant of exchange rate dynamics. We interpret this literature as evidence for a price elastic forex supply and explore its consequences for optimal international portfolio investment. The microstructure literature has always treated the forex order flows as exogenous model primitives and not itself as the object of equilibrium analysis. ${ }^{6}$ In our model forex order flow is derived endogenously from the optimal dynamic portfolio policy. Also the time horizon for our analysis extends to several months unlike the high frequency focus in many microstructure models. These models also typically involve informational asymmetries, which we omit to preserve simplicity and tractability.

Finally, our analysis relates to a recent literature on international equity flows. Some of this work is entirely descriptive (Bekaert and Harvey, (2000); Bekaert et al. (2002); Portes and Rey (1999); Richards (2002)). Brennan and Cao (1997) and Griffin et al. (2002) also provide a theoretical analysis of foreign investment behavior. Paradoxically, both treated foreign investment like domestic investment by modelling only dollar returns. Instead of an exchange rate, home and foreign investors are separated by information asymmetries (Brennan and Cao) or by exogenous differences in return expectations (Griffin et al.). Unlike these models, our framework assumes that foreign and home investors are separated by an exchange rate and pursue investment objectives in the currency of their respective residence.

\section{The Model}

A world with two countries has a home and a foreign investor. Both investors are risk averse and can invest in risky home and foreign equities and in riskless bonds. Equities pay a continuous stochastic dividend flow. Purchase of foreign equity is settled in foreign currency and therefore requires a parallel purchase of foreign currency in the forex market. Increases in foreign equity

product markets. Their set-up, centered around the bond market, does not however generate enough variability in exchange rate dynamics to match the data. Our model is not cast in a general equilibrium set up, since dividend processes and riskless rates are exogenous.

${ }^{6}$ Exceptions are Osler (1998) and Carlson and Osler (2000) who model the exchange rate as the price equating supply and demand on a foreign exchange market where 'current account traders' meet 'rational currency speculators'. 
holdings therefore generate an order flow ${ }^{7}$ in the forex market. Investors do not hold money balances, which are dominated by investment in the riskless bond. Foreign dividend income is either reinvested in foreign equity or repatriated for home country investment. Home investment can occur in home equity or a riskless bond with a constant interest rate. The supply of home and foreign equity is fixed and its price determined by market clearing. The bond supply is assumed to be infinitely price elastic. Central banks in both countries peg the interest rate.

We do not allow for short selling of foreign bonds. A short position in foreign bonds works as a forex hedge on the foreign equity investment. We believe that incomplete hedging of foreign investment is the more realistic benchmark compared to a world of full international exchange-rate risk sharing. It is important to highlight that the short sale constraint is binding in equilibrium (see proof in Appendix F). Intuitively, the home bond investment always strictly dominates the foreign bond investment under identical foreign and home bond returns and additional exchange rate risk on the foreign bond. Since home investors would like to hold a short position in foreign bonds to hedge the currency risk of their foreign equity position, but are prohibited from doing so, they can at best choose a zero position of foreign bonds. To simplify the exposition and reduce notation, we present the model as if investors were prevented from investing in foreign bonds altogether. This does not involve any loss of generality. Given that the short-selling constraint is always binding in equilibrium, we can assume zero foreign bond holdings.

The market structure is summarized as follows:

\section{Assumption 1: Asset Market Structure}

A home $(h)$ and a foreign $(f)$ stock market provide exogenous stochastic dividend flows $D_{t}^{h}$ and $D_{t}^{f}$ in local currency. Home and foreign investors can invest in both stock markets. In addition, each investor can invest in a domestic bond providing a riskless constant return $r$ in the respective local currency.

Investors in our model are risk averse and their objective is to find an optimal trade-off between expected profit flow of their asset position and the instantaneous profit risk. Each investor measures profits in home currency. Formally, we assume:

\section{Assumption 2: Investor Behavior}

Home and foreign investors are risk averse and maximize (in local currency terms) a mean-variance objective for the profit flow. ${ }^{8}$ Home investors choose a portfolio of

\footnotetext{
${ }^{7}$ We assume that when an agent purchases the foreign equity she initiates the purchase of foreign exchange, so that our net currency flow coincides with the conventional definition of the order flow (net of buyer over seller initiated trades).

${ }^{8}$ For the time horizons relevant for our exercise (1 day to several months), goods prices can be considered to be sticky in local currency.
} 
home and foreign equity, $K_{t}=\left(K_{t}^{h}, K_{t}^{f}\right)$, and foreign investors choose a portfolio of foreign and home equity, $K_{t}^{*}=\left(K_{t}^{f *}, K_{t}^{h *}\right)$, so as to solve the optimization problem

$$
\begin{array}{lll}
\max _{\left\{K_{t}^{h}, K_{t}^{f}\right\}} & \mathcal{E}_{t} \int_{s=t}^{\infty} e^{-r(s-t)} & {\left[d \Pi_{s}-\frac{1}{2} \rho d \Pi_{s}^{2}\right] d s} \\
\max _{\left\{K_{t}^{f *}, K_{t}^{h *}\right\}} & \mathcal{E}_{t} \int_{s=t}^{\infty} e^{-r(s-t)} & {\left[d \Pi_{s}^{*}-\frac{1}{2} \rho d \Pi_{s}^{* 2}\right] d s}
\end{array}
$$

where $\mathcal{E}_{t}$ denotes the rational expectation operator. Let $d R_{t}=\left(d R_{t}^{h}, d R_{t}^{f}\right)^{T}$ and $d R_{t}^{*}=\left(d R_{t}^{f *}, d R_{t}^{h *}\right)^{T}$ denote the corresponding excess payoffs (in local currency terms over the local riskless bond) for domestic and foreign investors, respectively. ${ }^{9}$ We define the stochastic profit flows for the domestic and foreign investors as

$$
\begin{aligned}
d \Pi_{t} & =K_{t} d R_{t} \\
d \Pi_{t}^{*} & =K_{t}^{*} d R_{t}^{*}
\end{aligned}
$$

respectively. The investor risk aversion is given by $\rho$, and the discount rate is given by $r .^{10}$

Both stock markets have to clear under the optimal asset demand. For simplicity we normalize the quantity of outstanding equity to one. This implies

$$
\begin{aligned}
& K_{t}^{h}+K_{t}^{h *}=1 \\
& K_{t}^{f}+K_{t}^{f *}=1
\end{aligned}
$$

as the two asset market clearing conditions.

An additional market clearing condition applies to the foreign exchange market with an exchange rate $E_{t}$. Denoting home and foreign equity prices by $P_{t}^{h}$ and $P_{t}^{f}$, respectively, we can measure the equity-related capital flows $d Q_{t}$ out of the home country (in foreign currency terms) as

$$
d Q_{t}=E_{t} K_{t}^{h *} D_{t}^{h} d t-K_{t}^{f} D_{t}^{f} d t+d K_{t}^{f} P_{t}^{f}-E_{t} d K_{t}^{h *} P_{t}^{h}
$$

The first two terms capture the outflow if all dividends are repatriated. But investors can also increase their holdings of foreign equity assets. The net purchases of foreign equity, $d K_{t}^{f}$ and $d K_{t}^{h *}$ are captured by the third and fourth terms. Let us for example denote the euro area as the foreign and the U.S. as the home country. Then $d Q_{t}$ represents the total net capital flow induced by equity trade (both dividend repatriation and net pruchases) by U.S. investors into

\footnotetext{
${ }^{9}$ The transposed vector is marked by ${ }^{T}$.

${ }^{10}$ The mean-variance objective here follows Hau (1998). It generates particularly tractable linear asset demands by ignoring intertemporal hedging. The dynamic CARA utility framework differs by an additional intertemporal hedging demand component proportional to the covariance between asset excess return and the state variables. Additional intertemporal hedging by investors may imply a smoother excess return dynamics but should not alter our results qualitatively.
} 
the euro area, in euro terms. An increase in $E_{t}$ (denominated in euro per dollar) corresponds to a dollar appreciation against the euro. Any net capital flow out of a country is, in our model, identical to a net demand for foreign currency as all investment is assumed to occur in local currency. We can therefore also identify $d Q_{t}$ with the equity trade induced order flow for foreign currency in the foreign exchange market. ${ }^{11}$ Furthermore, the above net capital flow out of the home country (or forex order flow) can be linearly approximated by

$$
d Q_{t}^{D}=\left(E_{t}-\bar{E}\right) \overline{K D} d t+\left(\bar{E} K_{t}^{h *}-K_{t}^{f}\right) \bar{D} d t+\left(\bar{E} D_{t}^{h}-D_{t}^{f}\right) \bar{K} d t+\left(d K_{t}^{f}-\bar{E} d K_{t}^{h *}\right) \bar{P} .
$$

where the upper bar variables denote the unconditional means of the stochastic variables. The linearization generates a linear order flow and renders the analysis tractable.

The net forex order flow of investors is absorbed by liquidity-supplying banks which can buffer foreign exchange imbalances. ${ }^{12}$ The following assumption characterizes the liquidity supply:

\section{Assumption 3: Price-Elastic Excess Supply of Foreign Exchange}

The foreign exchange market clears for a price-elastic excess supply curve with elasticity parameter $\kappa$. For an equilibrium exchange rate $E_{t}$, the excess supply of foreign exchange is given by

$$
Q_{t}^{S}=-\kappa\left(E_{t}-\bar{E}\right)
$$

where $\bar{E}$ denotes the steady state exchange rate level.

An increase in $E_{t}$ (euro depreciation) decreases the excess supply of euro balances. The exchange rate elastic excess supply captures incomplete intertemporal speculation of risk averse agents in the foreign exchange market, who sell dollars for euros when the dollar is high and buy dollars when the dollar is low. Liquidity supply is provided by different agents depending on the time horizon under consideration. Forex market makers take positions with half-lives measured in hours, while the half-lives of positions of proprietary trading desks, hedge funds and non-financial corporations are measured in days, weeks or months. Generally, intertemporal speculation involves considerable risk and needs to be compensated by expected trading profit. For example, if the exchange rate follows an Ornstein-Uhlenbeck process reverting to a (constant) equilibrium value $\bar{E}$, then the expected exchange rate change $\mathcal{E}_{t}\left(d E_{t}\right)$ and the expected instantaneous profit of liquidity supply $\mathcal{E}_{t}\left(d \Pi_{t}\right)=\mathcal{E}_{t}\left(Q_{t}^{S} d E_{t}\right)$ are proportional to the steady state deviation $\bar{E}-E_{t}$. The liquidity supply $Q_{t}^{S}$ should then increase in the steady state deviation

\footnotetext{
${ }^{11}$ Remember that there is no trade in the foreign riskless bond in equilibrium, so the forex order flow results only from equity trade and dividend repatriation.

${ }^{12} \mathrm{~A}$ generalization of the model consists in allowing for additional current account imbalances given by $C A_{t} d t=$ $\gamma\left(\bar{E}-E_{t}\right) d t$. The current account for the U.S. is in deficit when the dollar is strong and vice versa ( $\gamma$ is the exchange rate elasticity of the current account). This generalization is straightforward.
} 
$\bar{E}-E_{t}$. While it is possible to endogenize the elasticity parameter $\kappa$, we prefer the simpler parametric representation.

Market clearing in the forex market then requires $Q_{t}^{S}=Q_{t}^{D}$ and the foreign exchange rate is subject to the constraint

$$
-\kappa d E_{t}=\left(E_{t}-\bar{E}\right) \overline{K D} d t+\left(\bar{E} K_{t}^{h *}-K_{t}^{f}\right) \bar{D} d t+\left(\bar{E} D_{t}^{h}-D_{t}^{f}\right) \bar{K} d t+\left(d K_{t}^{f}-\bar{E} d K_{t}^{h *}\right) \bar{P} .
$$

The exchange rate dynamics is therefore tied to the relative dividend flows, $\bar{E} D_{t}^{h}-D_{t}^{f}$, the relative level of foreign asset holdings $\bar{E} K_{t}^{h *}-K_{t}^{f}$, and their relative changes $\bar{E} d K_{t}^{h *}-d K_{t}^{f}$. The relative dividend flows are exogenous, but the optimal relative foreign equity holdings are endogenously determined and depend in turn on the exchange rate dynamics. We normalize $\bar{E}$ to 1 , because the two countries are symmetrical.

It is straightforward to express the excess payoffs (over the riskless asset) on a unit of home equity over the interval $d t$ as $d R_{t}^{h}$. To characterize the foreign excess payoff $d R_{t}^{f}$ in home currency we use a linear approximation around the steady state exchange rate $\bar{E}=1$ and the steady state price $\bar{P}$. Formally, excess payoffs are given as

$$
\begin{aligned}
& d R_{t}^{h}=d P_{t}^{h}-r P_{t}^{h} d t+D_{t}^{h} d t \\
& d R_{t}^{f} \approx-d E_{t} \bar{P}+d P_{t}^{f}-d E_{t} d P_{t}^{f}-r\left[P_{t}^{f}-\bar{P}\left(E_{t}-1\right)\right] d t+\left[D_{t}^{f}-\bar{D}\left(E_{t}-1\right)\right] d t
\end{aligned}
$$

for the home and foreign assets, respectively. Excess returns follow as $d R_{t}^{h} / \bar{P}$ and $d R_{t}^{f} / \bar{P}$, respectively. The exchange rate component of the foreign payoff is given by $-\bar{P} d E_{t}$ and the exchange rate return by $-d E_{t} .^{13}$

Finally, we have to specify the stochastic structure of the state variables spelled out in the following assumption:

\section{Assumption 4: Stochastic Structure}

The home and foreign dividends follow independent Ornstein-Uhlenbeck processes with identical variance and mean reversion $\left(\alpha_{D}>0\right)$ given by

$$
\begin{aligned}
d D_{t}^{h} & =\alpha_{D}\left(\bar{D}-D_{t}^{h}\right) d t+\sigma_{D} d w_{t}^{h} \\
d D_{t}^{f} & =\alpha_{D}\left(\bar{D}-D_{t}^{f}\right) d t+\sigma_{D} d w_{t}^{f} .
\end{aligned}
$$

The innovations $d w_{t}^{h}$ and $d w_{t}^{f}$ are independent.

\footnotetext{
${ }^{13}$ The model is "closed" and there is no stock-flow inconsistency. A foreign equity purchase of the home investor is settled in foreign currency. But the foreign equity seller immediately reinvests this liquidity and holds zero money balances. He can either exchange it in the forex market if he reinvests in equity abroad, or bring it to his central bank at a fixed riskless rate. Central banks thus absorb the additional liquidity at the fixed rate $r$.
} 
The mean reversion of all stochastic processes simplify the analysis considerably. We can now introduce variables $F_{t}^{h}$ and $F_{t}^{f}$ which denote the expected present value of the future discounted dividend flow,

$$
\begin{aligned}
& F_{t}^{h}=\mathcal{E}_{t} \int_{s=t}^{\infty} D_{t}^{h} e^{-r(s-t)} d s=f_{0}+f_{D} D_{t}^{h} \\
& F_{t}^{f}=\mathcal{E}_{t} \int_{s=t}^{\infty} D_{t}^{f} e^{-r(s-t)} d s=f_{0}+f_{D} D_{t}^{f},
\end{aligned}
$$

with constant terms defined as $f_{D}=1 /\left(\alpha_{D}+r\right)$ and $f_{0}=\left(r^{-1}-f_{D}\right) \bar{D}$. The risk aversion of the investors and the market incompleteness with respect to forex risk trading imply that the asset price will generally differ from this fundamental value.

\section{Two Special Cases}

It is instructive to explore two special variations of our model. First we cover the extreme case in which no foreign asset holdings are allowed. We refer to this case as financial autarky. It provides a useful closed economy benchmark for the stock market equilibrium, in which investors do not internationally share their domestic equity risk. The opposite extreme assumption is to allow both the equity risk and the exchange rate risk to be fully and separately traded. This second benchmark characterizes the international financial market equilibrium with complete risk sharing. Formally, it is identical to an economy with two freely tradeable assets. The exchange rate is a redundant price. As empirically most relevant we consider a third case in which equity is freely traded but the exchange rate risk is not. We analyze this case in section 5 .

Solving the model always requires three steps. First, we postulate a linear solution for the asset prices and the exchange rate. Second, we derive the optimal asset demand under the conjectured solution. Third, we impose the market clearing conditions, show that the resulting price functions are indeed of the conjectured form and finally solve for the coefficients. To provide for a more coherent exposition, we summarize our results in various propositions. All derivations are relegated to appendices.

\subsection{Equilibrium without Risk Sharing (Financial Autarky)}

Under financial autarky, the home investor's foreign equity position $\left(K_{t}^{f}\right)$ and the foreign investor's home equity position $\left(K_{t}^{h *}\right)$ are assumed to be zero. All domestic assets are owned by domestic investors, hence

$$
\left(\begin{array}{cc}
K_{t}^{h} & K_{t}^{f} \\
K_{t}^{f *} & K_{t}^{h *}
\end{array}\right)=\left(\begin{array}{ll}
1 & 0 \\
1 & 0
\end{array}\right) .
$$


The financial market equilibrium for the home and foreign equity market can be determined separately. Proposition 1 states the result:

\section{Proposition 1: Equilibrium under Financial Autarchy.}

Assume a two-country world in which home investors hold the domestic asset and foreign investors the foreign asset. The home and foreign stock market prices are given by

$$
\begin{aligned}
P_{t}^{h} & =p_{0}+p_{F} F_{t}^{h} \\
P_{t}^{f} & =p_{0}+p_{F} F_{t}^{f}
\end{aligned}
$$

with $p_{0}=-\rho \sigma_{R}^{2} / r$ and $p_{F}=1$. The (instantaneous) return volatility follows as $\sigma_{R}^{2}=\sigma_{D}^{2} /\left(\alpha_{D}+r\right)^{2}$.

Proof: See Appendix A.

A price parameter $p_{F}=1$ implies that the asset prices are proportional to their fundamental values $F_{t}^{h}$ and $F_{t}^{f}$, respectively. The fundamental values represent the expected discounted future cash flows. The risk aversion of the investors is reflected in the coefficient $p_{0}<0$, which captures the equity risk premium as a price discount. It is proportional to the investor risk aversion $\rho$ and the instantaneous variance $\sigma_{R}^{2}$ of the excess return processes. These equilibrium results are standard for a closed economy with a fixed asset supply and mean-variance preferences for the investor.

\subsection{Equilibrium with Complete Risk Sharing}

A second model variation consists in the full risk sharing benchmark. Forex risk can then be fully traded either through derivative contracts or through short sales of the foreign riskless bond. Perfect and complete risk trading results in the elimination of all exchange rate risk. Intuitively, home and foreign investors hold exactly opposite and off-setting exchange rate risk in their global equity portfolio. They just need to swap the forex risk and thereby eliminate it. The resulting financial market equilibrium is stated in proposition 2 :

\section{Proposition 2: Equilibrium with Complete Risk Sharing.}

The home and foreign stock market prices and the exchange rate are given by

$$
\begin{aligned}
P_{t}^{h} & =p_{0}+p_{F} F_{t}^{h} \\
P_{t}^{f} & =p_{0}+p_{F} F_{t}^{f} \\
E_{t} & =1
\end{aligned}
$$


where we define $p_{0}=-\rho \sigma_{R}^{2} / 2 r$, and $p_{F}=1$. The (instantaneous) return volatility follows as $\sigma_{R}^{2}=\sigma_{D}^{2} /\left(\alpha_{D}+r\right)^{2}$. The domestic and foreign portfolio positions of the two investors are equal and constant with

$$
\left(\begin{array}{cc}
K_{t}^{h} & K_{t}^{f} \\
K_{t}^{f *} & K_{t}^{h *}
\end{array}\right)=\left(\begin{array}{cc}
\frac{1}{2} & \frac{1}{2} \\
\frac{1}{2} & \frac{1}{2}
\end{array}\right) .
$$

Proof: An identical riskless rate in the home and foreign country under complete markets implies a constant exchange rate, $E_{t}=1$. The complete solution is derived in Appendix B.

First, we note that the exchange rate is constant. In a world of perfect risk sharing, the two country model is not different from one domestic economy with two stocks. Home and foreign investors each hold equal and constant shares of the world market portfolio. The asset prices are again proportional to their fundamental values, $F_{t}^{h}$ and $F_{t}^{f}$, respectively. The risk sharing across the two investor groups implies that the asset price risk discount $p_{0}<0$ is only half as large as in the autarky case for the same return volatility $\sigma_{R}^{2}$. This implies lower average asset returns under market integration. Evidence that financial integration indeed reduces market stock returns is provided by Bekaert and Harvey (2000), Henry (2000) and Stulz (1999) among others. These authors show reduced capital costs or excess returns on equity for emerging countries following their capital market liberalization.

We further highlight that complete forex risk trading implies no particular correlation structure between exchange rate and equity returns. The exchange rate is a redundant price and constant. This implication is of course at odds with the high exchange rate volatility observed in practice. But it provides a useful benchmark for the following section which explores the case of equity market integration under incomplete exchange rate risk trading.

\section{$5 \quad$ Foreign Investment under Incomplete Risk-Sharing}

We now treat the case in which a foreign exchange market allows investment in the foreign equity, but exchange rate risk trading is incomplete. If the exchange rate moves stochastically, home investors with foreign equity holdings incur an additional exchange rate risk in addition to the risk of the stochastic dividend flow. Foreign investors hold the opposite risk due to ownership stakes in foreign equity. If this reciprocal exchange rate risk were tradeable, it could be perfectly eliminated as assumed in the perfect market case discussed in section 4.2. But now we assume that such forex risk trading does not occur.

The non-tradeability of the forex risk not only excludes derivative contracts, but also requires that investors cannot short sell the foreign riskless asset. Short selling of foreign riskless assets 
effectively amounts to a separate trading of the exchange rate risk. As discussed before, assuming a no short-sale constraint on the riskless foreign asset implies zero foreign bond holdings in equilibrium. If unconstrained, investors should seek a short position in the foreign riskless asset equivalent to their foreign equity stake. But they would not seek a long position which adds exchange rate risk to the portfolio. The short selling constraint is binding. Setting the foreign bond position to zero does not represent an additional restriction.

\subsection{Exchange Rate Dynamics}

Before we conjecture the exchange rate dynamics under incomplete markets, it is useful to highlight two principal equilibrium forces which shape this dynamics. The first equilibrium tendency is governed by the elastic liquidity supply for forex order flow. Forex order flow $d Q_{t}^{D}$ in equation (3) is accommodated by financial institutions which finance these home outflows according to an upward-sloping supply curve. The elasticity of forex liquidity supply certainly influences the impact of net order flow on the exchange rate and indirectly the adjustment speed towards the steady state exchange rate, $\bar{E}$. We associate the supply-induced mean reversion with a first characteristic root (labeled $z$ ). A second important parameter for exchange rate dynamics is the mean reversion of the dividend processes. This mean reversion $\alpha_{D}$ is exogenous, and any feedback effect from the exchange rate dynamics to the dividend process is ruled out by assumption.

An important simplifying feature of our model is its symmetry between the home and foreign country. Symmetry implies that the exchange rate can depend only on differences between home and foreign country variables, but not on a country-specific variable itself. Otherwise the symmetry would be broken. The symmetry requirement also implies that exchange rate

surprises can depend only on current and past relative dividend innovations, $d w_{s}=d w_{s}^{h}-d w_{s}^{f}$. These relative innovations are the only exogenous source of exchange rate dynamics.

Finally, we highlight the linearity of the model structure. The forex order flow constraint is linearized and the exogenous dividend dynamics is linear by assumption. Moreover, we have assumed a mean-variance utility function which translates linear dividend, price and return processes into linear asset demands. It is therefore justified to restrict our attention to the class of linear exchange rate and price processes. The argument for two fundamental equilibrium forces explains why we focus on two state variables $\Delta_{t}$ and $\Lambda_{t}$, both of which depend for reasons of model symmetry on current and past relative dividend innovations $d w_{s}$ only.

The following proposition 3 states the conjectured exchange rate process and derives its implications for the order flow constraint (4). 


\section{Proposition 3: Exchange Rate Dynamics.}

Assume that (i) equity prices $P=\left(P_{t}^{h}, P_{t}^{f}\right)$ depend linearly on the exchange rate $E_{t}$ and the dividend processes $D_{t}=\left(D_{t}^{h}, D_{t}^{f}\right)$ and (ii) the exchange rate has the following linear representation

$$
E_{t}=1+e_{\Delta} \Delta_{t}+e_{\Lambda} \Lambda_{t}
$$

with

$$
\begin{aligned}
\Delta_{t} & =D_{t}^{h}-D_{t}^{f}=\int_{-\infty}^{t} \exp \left[-\alpha_{D}(t-s)\right] \sigma_{D} d w_{s} \\
\Lambda_{t} & =\int_{-\infty}^{t} \exp [z(t-s)] d w_{s},
\end{aligned}
$$

where $z<0$ and $d w_{s}=d w_{s}^{h}-d w_{s}^{f}$. Then it follows that the order flow constraint (4) is of the simple form

$$
d E_{t}=k_{1} \Delta_{t} d t+k_{2}\left(E_{t}-1\right) d t+k_{3} d w_{t}
$$

where $k_{1}, k_{2}$ and $k_{3}$ represent undetermined coefficients.

Proof: The derivation is provided in Appendix C1. We have to show that for a linear price and a linear exchange rate, investor utility maximization implies optimal foreign equity demands $K_{t}^{h *}, K_{t}^{f}$ such that the expression $\left(K_{t}^{h *}-K_{t}^{f}\right) \bar{D} d t+\left(d K_{t}^{f}-d K_{t}^{h *}\right) \bar{P}$ in equation (4) is linear in $E_{t}-1, \Delta_{t}$ and $d w_{t}$.

Under linearity of the price and exchange rate processes, the order flow constraint simplifies to a differential equation in only two state variables $\Delta_{t}$ and $E_{t}-1$. This allows us to characterize the exchange rate dynamics as a system of two first-order differential equations,

$$
\left(\begin{array}{c}
d \Delta_{t} \\
d E_{t}
\end{array}\right)=\left(\begin{array}{cc}
-\alpha_{D} & 0 \\
k_{1} & k_{2}
\end{array}\right)\left(\begin{array}{c}
\Delta_{t} \\
E_{t}-1
\end{array}\right) d t+\left(\begin{array}{c}
\sigma_{D} \\
k_{3}
\end{array}\right) d w_{t}
$$

The associated characteristic polynomial follows as

$$
\left|\begin{array}{cc}
-\alpha_{D}-\lambda & 0 \\
k_{1} & k_{2}-\lambda
\end{array}\right|=\left(-\alpha_{D}-\lambda\right)\left(k_{2}-\lambda\right)=0,
$$

with characteristic roots $-\alpha_{D}$ and $k_{2}$. A stable solution requires $k_{2}<0$. The exchange rate solution can then be written as a linear combination $e_{\Delta} \Delta_{t}+e_{\Lambda} \Lambda_{t}$ of the two eigenvectors

$$
\Delta_{t}=\int_{-\infty}^{t} \exp \left[-\alpha_{D}(t-s)\right] \sigma_{D} d w_{s} \quad \text { and } \quad \Lambda_{t}=\int_{-\infty}^{t} \exp \left[k_{2}(t-s)\right] d w_{s}
$$

as conjectured in proposition 3 . 
In order to find the solution parameters, we have to impose the market clearing conditions (1) and determine the steady state levels for the equity price, $\bar{P}$, and the foreign equity holding, $\bar{K}$. Non-negative (steady state) prices $(\bar{P}>0)$ and positive (steady state) home and foreign equity holdings $(0<\bar{K}<1)$ imply further restrictions on the parameter domain of our model. In particular we have to impose an upper bound $\bar{\rho}$ on the risk aversion and a lower bound $\underline{\kappa}$ on the elasticity of the forex liquidity supply to obtain plausible steady state values.

Proposition 4 characterizes the equilibrium properties:

\section{Proposition 4: Existence and Uniqueness of the Incomplete Risk-Sharing Equilibrium.}

Let the economy be characterized by assumptions 1 to 4 . For a sufficiently low risk aversion of the investors $\rho<\bar{\rho}$ and a sufficiently price-elastic forex supply $\kappa>\underline{\kappa}$, there exists a unique stable linear equilibrium

$$
\begin{aligned}
P_{t}^{h} & =p_{0}+p_{F} F_{t}^{h}+p_{\Delta} \Delta_{t}+p_{\Lambda} \Lambda_{t} \\
P_{t}^{f} & =p_{0}+p_{F} F_{t}^{f}-p_{\Delta} \Delta_{t}-p_{\Lambda} \Lambda_{t} \\
E_{t} & =1+e_{\Delta} \Delta_{t}+e_{\Lambda} \Lambda_{t},
\end{aligned}
$$

where we define $F_{t}^{h}$ and $F_{t}^{f}$ as the expected present values of the future home and foreign dividend flows, respectively (as in section 3 ). The variable $\Delta_{t}=D_{t}^{h}-D_{t}^{f}$ represents the relative dividend flows for the two countries and $\Lambda_{t}$ a weighted average of past relative dividend innovations decaying at an endogenous rate $z<0$ as defined in proposition 3 . The price parameters can be signed as

$$
p_{0}<0, p_{F}=1, p_{\Delta}>0, e_{\Delta}<0, e_{\Delta} \sigma_{D}+e_{\Lambda}<0 .
$$

Optimal portfolio holdings are given by

$$
\left(\begin{array}{cc}
K_{t}^{h} & K_{t}^{f} \\
K_{t}^{f *} & K_{t}^{h *}
\end{array}\right)=\left(\begin{array}{cc}
1-\bar{K} & \bar{K} \\
1-\bar{K} & \bar{K}
\end{array}\right)+\left(\begin{array}{cc}
-1 & -1 \\
1 & 1
\end{array}\right) \frac{1}{2 \rho}\left(m_{\Delta} \Delta_{t}+m_{\Lambda} \Lambda_{t}\right)
$$

for the parameters $m_{\Delta}<0$, and $m_{\Lambda}>0$ defined in Appendix $\mathrm{C} 1$.

Proof: For a derivation see Appendix C.

As in the previous full risk-sharing case, we find that investor risk aversion requires an equity risk premium in the form of a price discount $p_{0}<0$. As before, a coefficient $p_{F}=1$ implies that the equity price reflects the fundamental value of expected future dividends, $F^{h}$ and $F_{t}^{f}$, respectively. Moreover, two new stochastic terms $\Delta_{t}$ and $\Lambda_{t}$ influence asset prices and the exchange rate. These additional terms reflect changes in the asset prices and exchange rate 
dynamics induced by the incompleteness of forex risk trading. The exchange rate is no longer constant and exchange rate volatility imply asymmetric holdings of home and foreign equity. In addition, the optimal portfolio positions change proportionally to $m_{\Delta} \Delta_{t}+m_{\Lambda} \Lambda_{t}$. The dynamic equilibrium is characterized by constant rebalancing of the optimal portfolios. We therefore have endogenous equity purchases and sales as a result of optimal equity risk trading under constrained forex risk trading. The net equity flows and the corresponding forex order flow in turn generate the equilibrium exchange rate dynamics under the price elastic forex liquidity supply.

\subsection{Economic Interpretation}

Investors in the two countries care about nominal trading profits in their home currency. This does not imply however that they only invest in home assets. Given that foreign asset investment provides an equity risk diversification benefit, foreign equity ownership is desirable for the home investor. But the foreign dividend income is repatriated at a fluctuating exchange rate. The exchange rate path is itself related to the relative performance of the two stock markets. For relatively high home dividend income $\left(\Delta_{t}=D_{t}^{h}-D_{t}^{f}>0\right)$, the home country faces a capital outflow approximated by the term $\left(D_{t}^{h}-D_{t}^{f}\right) \bar{K} d t$ in the flow constraint (4). This creates an excess demand for foreign currency. The value of the foreign currency should therefore be high (i.e. the value of the domestic currency should be low) under the limited supply elasticity in the forex market. The home stock price $P_{t}^{h}$ and exchange rate $E_{t}$ should therefore move in opposite directions. This explains the sign of the coefficients $p_{\Delta}>0$ and $e_{\Delta}<0$ in proposition 4. The country with a highly productive risky asset sees a decline in its currency terms of trade to assure the equilibrium in the forex market. We can formally summarize this effect as follows:

\section{Corollary 1: Negative Correlation of Foreign Stock and Forex Returns.}

Under incomplete forex risk trading, foreign stock returns $\left(d R_{t}^{f} / \bar{P}\right)$ and exchange rate returns $\left(-d E_{t}\right)$ are negatively correlated, hence

$$
-\mathcal{E}_{t}\left(d E_{t} d R_{t}^{f} / \bar{P}\right) d t=\mathcal{E}_{t}\left(d E_{t} d R_{t}^{h} / \bar{P}\right) d t<0 .
$$

Proof: Appendix E.

The negative correlation implies that the exchange rate provides a partial but automatic hedge against foreign equity risk. When foreign stock market returns are high, the foreign currency depreciates and vice versa. This reduces the return risk of foreign investment in home currency terms and increases the (steady state) demand for foreign equity. Furthermore, dividend processes are by assumption mean-reverting. When home dividends are high $\left(\Delta_{t}>0\right)$, they are expected to decrease and the home currency is therefore expected to appreciate. This 
makes the home equity at date $t$ more attractive relative to the foreign equity. It adds a price premium $\left(p_{\Delta} \Delta_{t}>0\right)$ to the home equity and a price discount $\left(-p_{\Delta} \Delta_{t}<0\right)$ to the foreign equity.

We highlight that the exchange rate more than adjusts to accommodate imbalances in foreign dividend income $\left(\Delta_{t}>0\right)$. If the exchange rate just counterbalanced high dividend outflows, the flow constraint (4) would only consist of the terms $-\kappa d E_{t}<0,\left(E_{t}-\bar{E}\right) \overline{K D} d t<0$ and $\left(D_{t}^{h}-D_{t}^{f}\right) \bar{K} d t>0$. But investors adjust their optimal portfolio holdings to the exchange rate dynamics and these equilibrium portfolio shifts influence the exchange rate change through the additional terms $\left(K_{t}^{h *}-K_{t}^{f}\right) \bar{D} d t$ and $\left(d K_{t}^{f}-d K_{t}^{h *}\right) \bar{P} d t$ in equation (4). A low home country exchange rate $\left(E_{t}\right.$ low) makes foreign equity holdings relatively more attractive for the home investor since the value of foreign dividends in domestic currency is high, implying $K_{t}^{h *}-K_{t}^{f}<0$ (or $m_{\Delta}<0$ ); an expected appreciation leads to a net equity flow into the domestic market $d K_{t}^{f}-d K_{t}^{h *}<0$. It follows from the flow constraint (4) that the endogenous portfolio shifts require a larger exchange rate appreciation $-\kappa d E_{t} \ll 0$ than is needed to eliminate the imbalance in dividend income. In this sense the exchange rate overshoots the dividend income imbalance. Optimal international portfolio allocations in the presence of incomplete forex risk trading therefore tend to reinforce the exchange rate fluctuations.

Finally, we also note that imperfect intertemporal forex speculation is a necessary condition for these results. This can be verified by examining the limiting case of a completely price-elastic forex liquidity supply. In this case the imperfect risk trading equilibrium converges to the special case of complete equity risk sharing:

\section{Proposition 5 (Convergence to Complete Risk Sharing):}

The incomplete risk-sharing equilibrium (characterized in proposition 4) converges to the complete risk-sharing equilibrium (characterized in proposition 2) as the currency supply becomes infinitely price elastic, that is $\kappa \rightarrow \infty$.

Proof: Appendix D.

In this limiting case, the investors can always exchange foreign dividend income at the constant exchange rate $\bar{E}=1$. Optimal international equity risk sharing is achieved by equally shared ownership of the world equity portfolio. The infinitely elastic currency supply corresponds to a scenario of perfect intertemporal speculation in the forex market. In practice, capital constraints for arbitraging speculators impose limits on the amount of intertemporal speculation (Shleifer and Vishny (1997)). A relatively small supply elasticity of currency may therefore represent the correct benchmark. 


\section{Model Implications}

We summarize the main empirical implications of our model, which concern the volatility of the exchange rate return relative to the equity return in section 6.1 , the correlation structure of exchange rate and equity returns in section 6.2 , and the correlation structure of exchange rate return and equity flows in section 6.3. We also discuss the effect of equity market development on the strength of our results in section 6.4.

\subsection{Exchange Rate Volatility}

Market completeness means that forex risk is widely and efficiently traded. Derivative trading or short-selling of bonds reallocate and largely eliminate the forex risk of all international equity investors. Moreover, a large number of market participants and their low aggregate risk aversion imply a very price-elastic forex supply. Home and foreign currency are then close substitutes. This limits the scope for forex order flow to generate considerable exchange rate volatility. Alternatively, if forex risk trading is restricted to a relatively small number of banks and hedge funds, then we expect a less price-elastic forex liquidity supply. In the latter case, forex order flow may result in considerable exchange rate movements.

Our model captures the elasticity of the forex supply in the parameter $\kappa$. Portfolio flows in the incomplete risk-sharing setting can generate considerable exchange rate volatility if $\kappa$ becomes small. We can illustrate this effect in Figure 1 by plotting the volatility ratio of the exchange rate returns and the stock market returns (in local currency),

$$
\sqrt{\frac{\operatorname{Var}\left(d E_{t}\right)}{\operatorname{Var}\left(d R_{t}^{f *} / \bar{P}\right)}},
$$

as a function of two fundamental model parameters, namely the investor risk aversion, $\rho$, and the elasticity of the liquidity supply, $\kappa$. The riskless rate $r$ and the three parameters governing the dividend processes $\left(\bar{D}, \alpha_{D}, \sigma_{D}\right)$ are held constant. The parameter range is given by $0.04<\rho<$ 0.44 for the degree of risk aversion and $20<\kappa<100$ for the liquidity supply parameter. A high price elasticity of forex liquidity supply ( $\kappa$ large) implies a low forex volatility. A decrease in the elasticity of the liquidity supply (lower $\kappa$ ) comes with substantial forex volatility as illustrated by the parametric plot. We summarize this result as follows:

\section{Implication 1: Exchange Rate Volatility.}

Market incompleteness in combination with a low price elasticity of forex liquidity supply can generate exchange rates which are almost as volatile as equity returns. 


\subsection{Equity Returns and Exchange Rate Returns}

Market incompleteness implies a negative correlation structure between foreign equity returns and exchange rate returns as stated in Corollary 1. Because of the symmetry of the model, it is most convenient to state the correlation structure for differences of the foreign and home equity returns in local currency, namely $\left(d R_{t}^{f *}-d R_{t}^{h}\right) / \bar{P}$. The following corollary provides the result:

\section{Corollary 2:}

Under incomplete forex risk trading, a foreign currency appreciation and foreign excess returns (in local currency) over home market returns have a perfect negative correlation, hence

$$
-\operatorname{Corr}\left[d E_{t},\left(d R_{t}^{f *}-d R_{t}^{h}\right) / \bar{P}\right]=-1
$$

Proof: See Appendix E.

For example, a U.S. equity market return shortfall relative to the European equity market $\left(\left(d R_{t}^{f *}-d R_{t}^{h}\right) / \bar{P}>0\right)$ should ceteris paribus coincide with a dollar appreciation $\left(d E_{t}>0\right)$. The negative correlation is perfect, because we have only two exogenous stochastic processes for the dividends which influence the model dynamics. For reasons of symmetry, return differences and exchange rate returns are driven exclusively by relative dividend innovations, $d w_{t}=d w_{t}^{h}-d w_{t}^{f}$. The instantaneous correlation between the local currency excess return can therefore only be either perfectly negative or positive or zero. Our analysis shows that the correlation is perfectly negative. Empirically, we cannot expect to find a perfectly negative correlation. Shocks other than dividend innovations and cross-country asymmetries will tend to reduce the absolute value of the correlation. As the empirically relevant implication, we therefore retain only the sign of the correlation:

\section{Implication 2: Differential Equity Returns and Foreign Exchange Rate Return}

When foreign stock index returns in (local currency) are in excess of the U.S. stock index returns (in dollars), the foreign currency depreciates.

To our knowledge, this particular correlation structure has not yet been related to financial structure in general and the incompleteness of forex risk trading in particular. We explore its empirical validity in section 7.2 .

\subsection{Exchange Rate Returns and Portfolio Flows}

Exchange rates in our model are determined through a price-elastic response to forex order flow, which in turn originates partly in equity flows. It therefore seems appropriate to relate exchange 
rate returns directly to equity portfolio flows. Using the price equilibrium in proposition 4, it is straightforward to show that the equity flows into the foreign market by home investors, $d K_{t}^{f}=-d K_{t}^{f *}$, and the equity flow into the home market by foreign investors, $d K_{t}^{h *}=-d K_{t}^{h}$, both correlate positively with the exchange rate return $-d E_{t}$ and $d E_{t}$, respectively. Formally,

$$
-\mathcal{E}\left(d E_{t} d K_{t}^{f}\right)=\mathcal{E}\left(d E_{t} d K_{t}^{h *}\right)=\frac{\kappa}{\bar{P}}\left(e_{\Delta} \sigma_{D}+e_{\Lambda}\right)^{2}>0 .
$$

The symmetry of the model implies that the exchange rate return has the same absolute covariance with foreign net purchases of domestic equities and with domestic net purchases of foreign equities, but with opposite signs. We can express the net equity flow into the foreign country as the difference $d K_{t}^{f}-d K_{t}^{h *}$. This net flow exhibits a perfect positive correlation with the exchange rate return. Hence the following corollary:

\section{Corollary 3:}

Under incomplete forex risk trading, a foreign currency appreciation and the net equity flow into the foreign country have a perfect positive correlation,

$$
-\operatorname{Corr}\left[d E_{t},\left(d K_{t}^{f}-d K_{t}^{h *}\right)\right]=1 .
$$

Proof: See Appendix E.

Again, the correlation is perfect, because all variables for country differences or the exchange rate are governed by stochastic innovations which are proportional to the relative dividend innovations, $d w_{t}=d w_{t}^{h}-d w_{t}^{f}$. Country heterogeneity in other dimensions will certainly tend to decrease the correlation to a value below 1 . We therefore retain only the sign of the correlation as the empirically relevant model implication and refer to the U.S. as the home country:

\section{Implication 3: Forex Return and Net Equity Flows.}

A foreign currency appreciation is positively correlated with net equity flows into the foreign market.

\subsection{The Role of Equity Market Development}

The correlation structure of equity and exchange rate returns was derived for integrated and frictionless equity markets. But equity market development and integration constitute a relatively recent phenomenon. Only in the 1990s did international equity trading become a prominent feature in international finance. Hence, we expect the empirical model implications to hold best for OECD country data over the last decade. We therefore examine the correlation structure separately over the entire data collection period and for two subsamples starting in 1990 and 
1995. An increasingly negative correlation between foreign excess equity returns and the foreign exchange rate return suggests that the correlation structure is indeed induced by increasing equity market integration.

Moreover, the evidence should be strongest for countries with relatively developed equity markets. Such equity market development can be crudely measured by the ratio of market capitalization to GDP. Alternatively, we can measure the integration of a local equity market into the world equity market by the ratio of gross equity trade to GDP. Both market development measures should be correlated with the magnitude of the predicted correlation structure. Such cross-sectional evidence suggests again that the exchange rate dynamics represents a financial market phenomenon.

We can summarize both the time series and cross sectional implications as follows:

\section{Implication 4: Negative Correlation and Equity Market Development.}

The magnitude of the negative correlation between foreign equity excess return and the exchange rate return should increase in the 1990s and should be strongest for countries with a high degree of equity market development as measured by the ratio of market capitalization to GDP or gross equity trade to GDP.

\section{Evidence}

The empirical work focuses on OECD countries relative to the U.S. OECD countries tend to have the most developed equity markets and are therefore most pertinent for the model. The U.S. represents by far the largest source and recipient of international equity flows. Furthermore, the most comprehensive bilateral asset flow data are available for the U.S. only. Within the OECD sample, we excluded three countries for which daily exchange rate data were not available over a sufficiently long time period: Iceland, Greece and New Zealand. Belgium and Luxemburg are treated as one country because of their common currency. Canada was excluded because of its effective exchange rate fixing with the U.S. ${ }^{14}$ The remaining 17 OECD countries maintained flexible exchange rates relative to the U.S. and constitute our sample.

The daily equity index and exchange rate data are obtained from Datastream. We used the MSCI series for the end of the day stock index quote and the corresponding dollar exchange rates. Most daily price data are available since 1980. The data are screened for data outliers and errors and do not show any abnormal entries.

Portfolio flow data are more difficult to obtain. We use the so-called TIC data produced by the U.S. Treasury department. Available on a monthly frequency since 1987, the TIC data record

\footnotetext{
${ }^{14}$ The same exchange rate consideration would also lead to the exclusion of Hong Kong and Singapore, which have developed equity markets but are not considered OECD countries.
} 
transactions in portfolio equities between U.S. residents and residents of foreign countries. ${ }^{15}$ They allow us to compute net purchases of foreign equities by U.S. residents $\left(d K_{t}^{f}\right)$ and net purchases of U.S. equities by foreigners $\left(d K_{t}^{h *}\right)$. Cross-border equity flows have been growing sizably in the last decade. ${ }^{16}$ Hence we have to find a suitable normalization of the portfolio flow series. We consider a normalization for capital flows by market capitalization and alternatively by the average flows over the previous 12 months (as in Brennan and Cao (1997)). Both methods produce very similar results and we only report tables with the normalization based on past average flows. The stock market capitalization data come from the S\&P Emerging Markets Database.

\subsection{Exchange Rate Volatility}

First, we examine the volatility ratio of exchange rate returns to stock index returns. We calculate the standard deviation of the log returns of the dollar exchange rate and the stock index returns in local currency. Table 1 reports the ratio of the standard deviations for the entire data sample since 1980 (column (a)), the subsample since 1990 (column (b)) and the most recent period since 1995 (column (c)).

The volatility ratio over the full sample varies between 0.369 for Finland and 0.845 for Switzerland with a mean for all countries of 0.6215 . Our theoretical framework can explain such high exchange rate volatility with a low price elasticity of the forex liquidity supply. Comparing volatility ratios for the entire period since 1980 to the more recent subsamples since 1990 and 1995, we find declining volatility ratios for most countries. This can mostly be attributed to a decrease in exchange rate volatility. We can speculate that the elasticity of liquidity supply in the forex market (parameter $\kappa$ in our model) might have increased over time. This would be consistent with increasing forex market depth in the more recent period.

\subsection{Equity Returns and Exchange Rate Returns}

The most important model implication concerns the negative correlation between foreign equity returns and exchange rate returns. We calculate the return correlations based on daily returns for various data periods. Exchange rate returns are in foreign currency per dollar and stock index returns are measured in local currency. The correlation evidence is produced at the daily,

\footnotetext{
${ }^{15}$ For a thorough presentation of these data see Warnock et al. (2001). We note that TIC data records transactions based on the residency of the seller and of the buyer. For example, a German equity sold in London by a U.S. resident to a U.K. Bank will be recorded as a sale of a foreign security by a U.S. resident to the U.K. In our model, this transaction will therefore be interpreted as a dollar pound transaction on the forex market. This inference can be flawed insofar as the real operation was actually performed in euro and not in Sterling or as it was realized on the behalf of a German equity trader.

${ }^{16}$ See Portes and Rey (1999) for a detailed study of the properties of these flows.
} 
monthly and quarterly frequency in Tables 2,3 and 4, respectively.

Daily correlations in Table 2 provides strong statistical evidence in favor of our correlation hypothesis. The model prediction of a negative correlation is validated for most countries at a 1 percent statistical significance level. ${ }^{17}$ Moreover, the correlations become more negative in the two more recent periods. The correlation in the pooled data decreases from -0.053 over the entire period to -0.0761 for the period since 1990 and to -0.0735 for the most recent period since 1995. The correlation has grown more negative along with the equity market integration, which has intensified since the 1990s. The only countries for which the correlation is still positive after 1995 are Australia and Japan. ${ }^{18}$ Overall, our evidence strongly supports the predicted negative correlation. Regression evidence on the pooled data sample shows a strong negative correlation significant at the 1 percent level. The monthly return data in Table 3 provide very similar results. In the sample period since 1995 every OECD country features a negative correlation at the monthly frequency. Again we find that the correlation became more negative in the 1990s. For the entire data collection period from 1973 to 2002, the correlation is roughly half as strong as in the last decade.

Table 4 confirms our results on quarterly data for the period 1990 to 2002 . We present regressions of exchange rate changes on return differentials for all the countries of our sample. The correlation is again negative and strongly significant for most countries. Furthermore, the variance of the exchange rate explained by our simple return differential variable is strikingly high for some countries. With a single variable, namely equity return differential, we explain 30 percent of quarterly exchange rate movements in Spain, 28 percent in Sweden, 25 percent in Germany. For the pooled data the $R^{2}$ is 13 percent. These results offer a sharp contrast with the dismal performance of monetary variables in standard exchange rate models at quarterly horizons.

The negative correlation has previously been noted by other researchers for some particular countries. But they were mostly puzzled by the lack of a coherent theoretical explanation. Brooks et al. (2001) for example document negative correlations between European equity excess returns over U.S. equity and the euro-dollar exchange rate. Interestingly, they discard their finding as "counter-intuitive" (p. 17), since it contradicts the popular view that a strengthening U.S. equity market should be mirrored by a strengthening of the dollar. ${ }^{19}$ Incomplete forex

\footnotetext{
${ }^{17}$ Standards errors are corrected for heteroskedasticity and serial correlation.

${ }^{18}$ We conjecture that the Australian evidence might be tainted by the role of natural resource prices. Chen and Rogoff (2001) and Cashin, Cespedes and Sahay (2002) show indeed that the Australian exchange rate is strongly related to world commodity price fluctuations. They underline the specificity of this country in this respect. Japan on the other hand is special because international portfolio flows concern mostly bonds as opposed to equity.

${ }^{19}$ Lane and Milesi-Ferretti (2002) also report a negative correlation between domestic real return in local currency and the real exchange rate at the yearly horizon.
} 
risk trading offers a coherent theoretical explanation for the observed correlation structure. From an empirical perspective, the negative correlation deserves to be highlighted because of its strong statistical significance and increasing magnitude. Moreover, it stands out relative to the empirical failure of uncovered interest parity for the same set of countries. ${ }^{20}$

\subsection{Exchange Rate Returns and Portfolio Flows}

Data on equity flows allow for another test of our model. Model implication 3 highlights a positive correlation between equity investment into the foreign market and the foreign currency return. Data on bilateral equity flows relative to the U.S. are unfortunately available only at the monthly frequency. Table 5 summarizes the evidence on the correlation of net U.S. flows into the same 17 OECD countries as before and the corresponding foreign exchange rate returns.

Only France and Portugal show positive correlation at the 1 percent significance level for the entire data period since 1987. Pooling the entire data for all countries even produces a negative, albeit insignificant, correlation. However, this picture is reversed for the more recent data period since 1990. The correlation is now significantly positive at the 1 percent level for 6 countries. It is positive but insignificant for 4 others. The correlation for the pooled sample increases to 0.114 and is statistically significant at the 1 percent level. Overall, the evidence is supportive of a linkage between net equity portfolio flows and exchange rate returns. Net equity flows into the foreign market tend to appreciate the foreign currency.

\subsection{Equity Market Development and the Correlation Structure}

The evidence in Tables 2, 3 and 4 suggest that foreign equity excess returns became a more important determinant of exchange rate behavior in the 1990s, presumably because of increased equity market development and integration. We can test this hypothesis further by examining the cross sectional variation of equity market development within the OECD sample. Two crude measures of equity market development are given by the quarterly market capitalization of the OECD country relative to its GDP and by the gross equity trade with the U.S. relative to GDP. These measures of equity market development are highly correlated at 0.84 .

Figure 2 plots the average monthy correlation between local equity excess returns (over U.S. returns) and FX returns for the 17 countries as a function of the (log) market capitalization to GDP ratio for the sample period 1995-2001. Countries with higher equity market development tend to show a more negative correlation between their equity market excess return and the

\footnotetext{
${ }^{20}$ One could theoretically offer an alternative hypothesis for this negative correlation. A depreciation of the exchange rate could be associated with higher equity returns via a competitiveness effect for exporting firms. Such a mechanism has failed to find strong support in previous empirical studies (see in particular Bodnar and Gentry (1993) and Friberg and Nydahl (1999)). Moreover, that alternative explanation could not account for intertemporal increase in the correlation.
} 
exchange rate return. We can analyze this link further using panel regressions reported in Table 6. We calculate quarterly realized correlations from daily returns for all 17 OECD countries and regress those alternatively on both measures of market development and a fixed time effect for each quarter. Both market development proxies are statistically significant at a 1 percent level. We conclude that the correlation structure of equity and exchange rate returns is related to the level of equity market development. The correlation is more negative for OECD countries with the most developed equity markets.

\section{Conclusion}

This paper develops a new integrated analysis of exchange rates, equity prices and equity portfolio flows. Such a framework is warranted by the increasing magnitude of international equity flows over the last decade. We argue that the integration of equity markets does not imply convergence to a financial structure based on full exchange rate risk trading. The available evidence from U.S. global mutual funds suggests to the contrary that forex risk in international equity portfolios is mostly unhedged and therefore not internationally traded. The main theoretical contribution of this paper is to explore the implications of incomplete forex risk trading for the correlation structure of exchange rate and equity returns and exchange rate returns and net portfolio flows.

The theoretical analysis incorporates a stylized fact from the recent microstructure research on exchange rates, namely that net forex order flow tends to generate large and relatively persistent exchange rate changes. We simply assume a price elastic forex supply curve to mimic this exchange rate reaction. But the forex order flow itself is tied to the endogenous portfolio flows which emerge under optimal dynamic investment in an incomplete market setting. The entire exchange rate dynamics is therefore based exclusively on the financial market structure as opposed to traditional macroeconomic determinants.

We highlight three dimensions in which this parsimonious approach is successful. First, the model can explain a large degree of exchange rate volatility if the elasticity of forex liquidity supply is sufficiently low. Second, we derive a negative correlation between foreign equity excess returns (in local currency) and the corresponding exchange rate returns. This correlation contradicts the conventional belief that strong equity markets are accompanied by currency appreciation. This correlation structure has not been highlighted in the previous exchange rate literature. Such a negative correlation decreases the risk of foreign investment in home currency terms as negative foreign equity returns tend to be compensated by positive exchange rate returns. This automatic hedge reduces the home bias and facilitates international equity risk sharing. We find very strong empirical support for the predicted return correlation at daily, 
monthly and quarterly horizons. Stock return differentials explain as much as 30 percent of the variance of the exchange rate at the quarterly frequency for some countries. Moreover, the negative correlation becomes more pronounced after 1990, perhaps because of more developed and integrated international equity markets. The cross-sectional evidence also points to the role of financial market development. Countries with a higher equity market capitalization relative to GDP tend to have a more negative return correlation. Third, we explore the correlation between exchange rate returns and net equity flows. The model predicts a positive correlation since net equity flows are tied to forex order flows. The period after 1990 shows a highly significant positive correlation for the pooled data of 17 OECD countries.

Our analysis can be extended in various directions. We believe that the results are robust to positive correlation between home and foreign dividends. Dividends were so far assumed to be independent. But such internationally correlated equity market risk is per se devoid of risk trading benefits and should not alter the allocation problem for the remaining uncorrelated equity return risk. A more interesting extension would take account of asymmetric information or differences in opinion concerning the international equity returns between the home and foreign investors. This would introduce an additional and potentially important new trading motive alongside the equity risk sharing concerns of the present framework. 


\section{References}

[1] Bekaert, G. and Harvey, C. (2000). 'Foreign speculators and emerging equity markets', Journal of Finance, 55(2), 565-613.

[2] Bekaert, G., C. R. Harvey, and R. L. Lumsdaine (2002). 'The dynamics of emerging market equity flows', Journal of International Money and Finance, forthcoming.

[3] Bodnar, G. and W. Gentry (1993). 'Exchange rate exposure and industry characteristics: evidnce from Canada, Japan and the USA', Journal of International Money and Finance. $44,1755-1785$.

[4] Board of Governors of the Federal Reserve System (2000). 'Report on U.S. holdings of foreign long-term securities', Washington DC.

[5] Branson W., and W. Henderson (1985). 'The specification and influence of asset markets', in Jones, R. and P. Kenen (eds.), Handbook of International Economics, North-Holland.

[6] Brennan, M. J., and H. H. Cao (1997), 'International portfolio investment flows', Journal of Finance, Vol. 52, 1851-1880.

[7] Brooks R., H. Edison, M. Kumar and T. Slok (2001). 'Exchange rates and capital flows', IMF working paper WP/01/190.

[8] Cashin, Cespedes and Sahay (2002). 'Keynes, cocoa and copper: in search of commodity currencies', IMF mimeo.

[9] Carlson J. and C. Osler (2000). 'rational speculators and exchange rate volatility', European Economic Review 44, February: 231-253.

[10] Chen Y. and K. Rogoff (2001). 'Commodity currencies and empirical exchange rate equations', IMF mimeo.

[11] Chowdry B., R. Roll and Y. Xia (2002). 'Extracting inflation from stock returns to test Purchasing Power Parity', Wharton mimeo.

[12] Diebold F., T. Andersen, T. Bollerslev and H. Ebens (2001). 'The distribution of realized stock return volatility', Journal of Financial Economics, Vol. 61, No1, 43-76.

[13] Duarte M. and A. Stockman (2001). 'Rational speculation and exchange rates', NBER WP 8362.

[14] Devereux M, and C. Engel (2002). 'Exchange rate pass-through, exchange rate volatility, and exchange rate disconnect', mimeo University of Wisconsin. 
[15] Evans M. (2002). 'FX trading and exchange rate dynamics', Journal of Finance, forthcoming.

[16] Evans M. and R. Lyons (2001a). 'Order flow and exchange rate dynamics', (NBER WP 7317), Journal of Political Economy, 2002.

[17] Evans M. and R. Lyons (2001b). 'Why order flow explains exchange rate', available at http://haas.berkeley.edu/ lyons.

[18] Frankel J. (1994). 'The internationalization of equity markets', University of Chicago Press, $1-20$.

[19] Frankel J. and A. Rose (1995). 'Empirical research on nominal exchange rates', in G. Grossman and K.Rogoff (eds.), Handbook of International Economics, North-Holland.

[20] Friberg R. and S. Nydahl (1999). Openness and the exchange rate exposure of the national stock markets, International Journal of Finance and Economics 4, 55-62.

[21] Froot, K., P. O'Connell, and M. Seasholes (2001). 'The portfolio flows of international investors', Journal of Financial Economics, 59, 151-193.

[22] Froot, K and T. Ramadorai (2002). 'Currency returns, institutional investors flows, and exchange rate fundamentals', NBER WP 9101.

[23] Griffin J., F. Nardari and R. Stulz (2002). 'Daily cross-border equity flows: pushed or pulled?', mimeo.

[24] Hau, H. (1998). 'Competitive entry and endogenous risk in the foreign exchange market', Review of Financial Studies, Vol. 11, No. 4, 757-787.

[25] Hau, H., W. Killeen, and M. Moore (2002). 'How has the euro changed the foreign exchange market?', Economic Policy 34, April, 151-177.

[26] Henry, P. B., (2000). 'Do stock market liberalizations cause investment booms?', Journal of Financial Economics, 58(1-2), 301-334.

[27] Killeen, W., R. Lyons, and M. Moore, (2001). 'Fixed versus floating: lessons from the EMS order flow', Paper presented at the NBER IFM conference, available at http://haas.berkeley.edu/ lyons.

[28] Lane, P. and G.M. Milesi-Ferreti (2002), 'Global financial integration', paper presented at the 2002 IMF Research Conference. 
[29] Levich, R. M., G. S. Hayt, and B. A. Ripston (1999), '1998 survey of derivative and risk management practices by U.S. institutional investors', survey conducted by the NYU Salomon Center, CIBC World Markets, and KPMG, available at http://www.stern.nyu.edu/ ${ }^{\sim}$ rlevich/.

[30] Lucas, R. (1982). 'Interest rates and currency prices in a two-country world'.

[31] Lyons, R. (2001). The microstructure approach to exchange rates, MIT Press.

[32] Meese R. and K. Rogoff (1983a). 'Empirical exchange rate models of the seventies: do they fit out-of-sample?', Journal of International Economics, February, 14(2), 3-24.

[33] Meese R. and K. Rogoff (1983b). 'The out-of-sample failure of empirical exchange rate models: sampling error or misspecification?', in Jacob A. Frenkel (eds.), pp 67-105.

[34] Obstfeld M. and K. Rogoff (1995).'Exchange rate dynamics redux', Journal of Political Economy, 103 (June) : 624-60.

[35] Obstfeld M. and A. Taylor (2002): 'Globalization and capital markets', NBER WP 8846.

[36] Osler, C. (1998). 'Short-term speculators and the puzzling behavior of exchange Rates', Journal of International Economics 43, No. 1, June : 37-58.

[37] Portes R. and H. Rey (1999). 'The determinants of cross-border equity flows', NBER WP 7336.

[38] Richards A. (2002). 'Big fish in small ponds: the momentum investing and price impact of foreign investors in Asian emerging equity markets', mimeo.

[39] Rime D. (2001). 'Trading in foreign exchange markets', PhD Thesis, Norwegian School of Management.

[40] Shleifer, A. and R.W. Vishny (1997), The limits of arbitrage, Journal of Finance, Vol. 52, No.1, 35-55.

[41] Warnock F., B. Griever and G. Lee (2001). 'The U.S. System for Measuring Cross-Border Investment in Securities: A Primer with a Discussion of Recent Developments', Federal Reserve Bulletin, October. 


\section{Appendix A: Equilibrium under Financial Autarchy}

\section{Proposition 1:}

Let $F_{t}^{h}=f_{0}+f_{D} D_{t}^{h}$ denote the fundamental equity value in the home country with $f_{D}=1 /\left(\alpha_{D}+r\right)$ and $f_{0}=\left(r^{-1}-f_{D}\right) \bar{D}$.

We conjecture a linear price equilibrium of the form

$$
\begin{aligned}
& P_{t}^{h}=p_{0}+p_{F} F_{t}^{h} \\
& P_{t}^{f}=p_{0}+p_{F} F_{t}^{f} .
\end{aligned}
$$

The excess payoffs over the risk-less rate of home country equity follows as

$$
d R_{t}^{h}=d P_{t}^{h}-r P_{t}^{h} d t+D_{t}^{h} d t=\boldsymbol{\alpha}_{\Psi}^{h} \Psi_{t}^{h} d t+b_{\Psi}^{h} d w_{t}^{h}
$$

with $\mathbf{\Psi}_{t}^{h}=\left(1, D_{t}^{h}\right)^{T}$ and coefficients $\boldsymbol{\alpha}_{\Psi}^{h}=\left(-r p_{0}, 1-p_{F}\right)$ and $b_{\Psi}^{h}=p_{F} f_{D} \sigma_{D}$.

The optimal asset demand for investors is given by

$$
K_{t}^{h}=\frac{\mathcal{E}_{t}\left(d R_{t}^{h}\right)}{\rho \sigma_{R}^{2} d t}
$$

with $\sigma_{R}^{2} d t=\mathcal{E}_{t}\left(d R_{t}^{h}\right)^{2}$. Market clearing requires $K_{t}^{h}=1$ and implies for the price coefficients

$$
\begin{aligned}
& p_{0}=-\frac{\rho \sigma_{R}^{2}}{r} \\
& p_{F}=1 .
\end{aligned}
$$

The same price parameters are obtain for the foreign stock market. The instantaneous volatility of the excess pay-off is given by

$$
\sigma_{R}^{2}=\left(b_{\Psi}^{h}\right)^{2}=\frac{\sigma_{D}^{2}}{\left(\alpha_{D}+r\right)^{2}}
$$

\section{Appendix B: Equilibrium under Complete Risk-Sharing}

\section{Proposition 2:}

We conjecture a linear price system of the form

$$
\begin{aligned}
P_{t}^{h} & =p_{0}+p_{F} F_{t}^{h} \\
P_{t}^{f} & =p_{0}+p_{F} F_{t}^{f} \\
E_{t} & =1 .
\end{aligned}
$$

As before, we denote by $F_{t}^{h}=f_{0}+f_{D} D_{t}^{h}$ and $F_{t}^{f}=f_{0}+f_{D} D_{t}^{f}$ the fundamental values of the two risky assets. The home country investor faces excess payoffs $R_{t}^{h}$ and $R_{t}^{f}$ for home and foreign equity, respectively. The foreign country investor (denoted by ${ }^{*}$ ) faces excess payoffs (in foreign currency) $R_{t}^{f *}$ and $R_{t}^{h *}$ for foreign and home country equity, respectively. Linear approximations allow us to write:

$$
\begin{aligned}
d R_{t}^{h} & =d P_{t}^{h}-r P_{t}^{h} d t+D_{t}^{h} d t \\
d R_{t}^{f} & \approx-d E_{t} \bar{P}+d P_{t}^{f}-d E_{t} d P_{t}^{f}-r\left[P_{t}^{f}-\bar{P}\left(E_{t}-1\right)\right] d t+\left[D_{t}^{f}-\bar{D}\left(E_{t}-1\right)\right] d t \\
d R_{t}^{f *} & =d P_{t}^{f}-r P_{t}^{f} d t+D_{t}^{f} d t \\
d R_{t}^{h *} & \approx d E_{t} \bar{P}+d P_{t}^{h}+d E_{t} d P_{t}^{h}-r\left[P_{t}^{h}+\bar{P}\left(E_{t}-1\right)\right] d t+\left[D_{t}^{h}+\bar{D}\left(E_{t}-1\right)\right] d t .
\end{aligned}
$$


The constant exchange rate $\left(d E_{t}=0\right)$ implies that payoffs in foreign currency terms are equal to home currency payoffs, hence $d R_{t}^{h *}=d R_{t}^{h}$, and $d R_{t}^{f *}=d R_{t}^{f}$. The excess payoffs take on the simple form

$$
\begin{aligned}
d R_{t}^{j} & =\boldsymbol{\alpha}_{\Psi}^{j} \mathbf{\Psi}_{t}^{j} d t+b_{\Psi}^{j} d w_{t}^{j} \\
d R_{t}^{j *} & =\boldsymbol{\alpha}_{\Psi}^{j *} \boldsymbol{\Psi}_{t}^{j} d t+b_{\Psi}^{j *} d w_{t}^{j}
\end{aligned}
$$

where $j=h, f$ denotes the country index, $\boldsymbol{\Psi}_{t}^{j}=\left(1, D_{t}^{j}\right)^{T}$ the state variable and $\boldsymbol{\alpha}_{\Psi}^{j}=\boldsymbol{\alpha}_{\Psi}^{j *}=\left(\alpha_{0}^{j}, \alpha_{D}^{j}\right)$, $b_{\Psi}^{j}=b_{\Psi}^{j *}$ coefficients.

Finally, we consider the correlation structure of the payoffs. Let $\Omega d t$ denote the covariance matrix of the excess payoffs $\left(d R_{t}^{h}, d R_{t}^{f}\right)$ (in home currency terms) for the home investor and $\Omega^{*} d t$ the corresponding covariance matrix of the excess payoffs $\left(d R_{t}^{f *}, d R_{t}^{h *}\right)$ (in foreign currency) for the foreign investor. Symmetry of the two country model implies

$$
\Omega=\Omega^{*}=\left(\begin{array}{cc}
\Omega_{11} & \Omega_{21} \\
\Omega_{21} & \Omega_{22}
\end{array}\right), \quad \Omega^{-1}=\left(\Omega^{*}\right)^{-1}=\frac{1}{\operatorname{det} \Omega}\left(\begin{array}{cc}
\Omega_{22} & -\Omega_{21} \\
-\Omega_{21} & \Omega_{11}
\end{array}\right)
$$

with $\operatorname{det} \Omega=\Omega_{11} \Omega_{22}-\Omega_{21} \Omega_{21}$.

For the special case of complete markets with a constant exchange rate, we have $\mathcal{E}_{t}\left(d E_{t} d P_{t}^{h}\right)=0$, $\Omega_{21}=0$, and $\Omega_{11}=\Omega_{22}=\sigma_{R}^{2}$. Therefore,

$$
\Omega^{-1}=\frac{1}{\sigma_{R}^{4}}\left(\begin{array}{cc}
\Omega_{11} & 0 \\
0 & \Omega_{22}
\end{array}\right)=\frac{1}{\sigma_{R}^{2}}\left(\begin{array}{ll}
1 & 0 \\
0 & 1
\end{array}\right)=\frac{1}{\sigma_{R}^{2}} \mathbf{1}_{2 \times 2} .
$$

The first-order condition for the asset demands is given by

$$
\left(\begin{array}{cc}
K_{t}^{h} & K_{t}^{f} \\
K_{t}^{f *} & K_{t}^{h *}
\end{array}\right)=\frac{1}{\rho d t} \mathcal{E}_{t}\left(\begin{array}{cc}
d R_{t}^{h} & d R_{t}^{f} \\
d R_{t}^{f *} & d R_{t}^{h *}
\end{array}\right) \Omega^{-1} .
$$

Market clearing in the two stock markets $\left(K_{t}^{h}+K_{t}^{h *}=1, K_{t}^{f}+K_{t}^{f *}=1\right)$ implies the price coefficients

$$
\begin{aligned}
& p_{0}=-\frac{\rho \sigma_{R}^{2}}{2 r} \\
& p_{F}=1 .
\end{aligned}
$$

For the optimal portfolio positions we obtain

$$
\left(\begin{array}{cc}
K_{t}^{h} & K_{t}^{f} \\
K_{t}^{f *} & K_{t}^{h *}
\end{array}\right)=\left(\begin{array}{cc}
\frac{1}{2} & \frac{1}{2} \\
\frac{1}{2} & \frac{1}{2}
\end{array}\right)
$$

Hence the existence and uniqueness of the complete risk-sharing equilibrium (Proposition 2).

\section{Appendix C: Equilibrium under Incomplete Risk-Sharing.}

We prove the existence of the equilibrium under incomplete risk-sharing and its uniqueness in the class of linear equilibria. We proceed in four steps: 1) using our guessed solutions for exchange rates and equity prices, we derive optimal asset demands and the differential system governing the dynamics of our model (Appendix C1, proposition 3 in the paper); 2) we impose market clearing and identify the 
parameters (Appendix C2); 3) we show the existence and uniqueness of $z$ (Appendix C3); 4) we show the existence and uniqueness of all the other parameters, thereby establishing the existence and uniqueness of the equilibrium (Appendix C4, proposition 4 in the paper).

\section{C1. Exchange Rate Dynamics}

\section{Proposition 3 :}

We assume that the exchange rate process is of the form $E_{t}=1+e_{\Delta} \Delta_{t}+e_{\Lambda} \Lambda_{t}$. and that equity prices have the following representation

$$
\begin{aligned}
P_{t}^{h} & =p_{0}+p_{F} F_{t}^{h}+p_{\Delta} \Delta_{t}+p_{\Lambda} \Lambda_{t} \\
P_{t}^{f} & =p_{0}+p_{F} F_{t}^{f}-p_{\Delta} \Delta_{t}-p_{\Lambda} \Lambda_{t} .
\end{aligned}
$$

Let $j=h, f$ denote the country index, $\Psi_{t}^{j}=\left(1, D_{t}^{j}, \Delta_{t}, \Lambda_{t}\right)^{T}$ the state variable, $\mathbf{d w}_{t}^{j}=\left(d w_{t}^{j}, d w_{t}\right)^{T}=$ $\left(d w_{t}^{j}, d w_{t}^{h}-d w_{t}^{f}\right)^{T}$ a $(1 \times 2)$ vector of innovations. For coefficients $\boldsymbol{\alpha}_{\Psi}^{j}=\left(\alpha_{0}^{j}, \alpha_{D}^{j}, \alpha_{\Delta}^{j}, \alpha_{\Lambda}^{j}\right), \boldsymbol{\alpha}_{\Psi}^{j *}=$ $\left(\alpha_{0}^{j *}, \alpha_{D}^{j *}, \alpha_{\Delta}^{j *}, \alpha_{\Lambda}^{j *}\right), \mathbf{b}_{\Psi}^{j}=\left(p_{F} f_{D} \sigma_{D}, b_{\Psi}^{j}\right), \mathbf{b}_{\Psi}^{j *}=\left(p_{F} f_{D} \sigma_{D}, b_{\Psi}^{j *}\right)$ we express excess payoffs as

$$
\begin{aligned}
d R_{t}^{j} & =\boldsymbol{\alpha}_{\Psi}^{j} \boldsymbol{\Psi}_{t}^{j} d t+\mathbf{b}_{\Psi}^{j} \mathbf{d} \mathbf{w}_{t}^{j} \\
d R_{t}^{j *} & =\boldsymbol{\alpha}_{\Psi}^{j *} \Psi_{t}^{j} d t+\mathbf{b}_{\Psi}^{f *} \mathbf{d} \mathbf{w}_{t}^{j}
\end{aligned}
$$

and the first-order conditions imply for the optimal asset demand

$$
\left(\begin{array}{cc}
K_{t}^{h} & K_{t}^{f} \\
K_{t}^{f *} & K_{t}^{h *}
\end{array}\right)=\frac{1}{\rho d t} \mathcal{E}_{t}\left(\begin{array}{cc}
\boldsymbol{\alpha}_{\Psi}^{h} \Psi_{t}^{h} & \boldsymbol{\alpha}_{\Psi}^{f} \boldsymbol{\Psi}_{t}^{f} \\
\boldsymbol{\alpha}_{\Psi}^{f *} \Psi_{t}^{f} & \boldsymbol{\alpha}_{\Psi}^{h *} \Psi_{t}^{h}
\end{array}\right) \Omega^{-1}
$$

Market clearing $\left(K_{t}^{h}+K_{t}^{h *}=1, K_{t}^{f *}+K_{t}^{f}=1\right)$ gives

$$
\begin{aligned}
K_{t}^{h *}-K_{t}^{f} & =\frac{1}{\rho}\left[m_{\Delta} \Delta_{t}+m_{\Lambda} \Lambda_{t}\right] \\
d K_{t}^{h *}-d K_{t}^{f} & =\frac{1}{\rho}\left[-\alpha_{D} m_{\Delta} \Delta_{t} d t+z m_{\Lambda} \Lambda_{t} d t\right]+\frac{1}{\rho}\left[m_{\Delta} \sigma_{D}+m_{\Lambda} \sigma_{\Lambda}\right] d w_{t}
\end{aligned}
$$

where we define the coefficients

$$
\begin{aligned}
m_{\Delta} & =2 p_{\Delta}\left(\alpha_{D}+r\right)\left(\Omega_{12}^{-1}-\Omega_{22}^{-1}\right)-2 m_{\alpha} e_{\Delta} \Omega_{22}^{-1} \\
m_{\Lambda} & =2 p_{\Lambda}(-z+r)\left(\Omega_{12}^{-1}-\Omega_{22}^{-1}\right)-2 m_{z} e_{\Lambda} \Omega_{22}^{-1} \\
m_{\alpha} & =\left(\alpha_{D}+r\right) \bar{P}-\bar{D} \\
m_{z} & =(-z+r) \bar{P}-\bar{D}
\end{aligned}
$$

Finally, we replace

$$
\Lambda_{t}=\frac{1}{e_{\Lambda}}\left(E_{t}-\bar{E}\right)-\frac{e_{\Delta}}{e_{\Lambda}} \Delta_{t}
$$

and find that the term $\left(K_{t}^{h *}-K_{t}^{f}\right) \bar{D} d t+\left(d K_{t}^{f}-d K_{t}^{h *}\right) \bar{P}$ is linear in $E_{t}-\bar{E}, \Delta_{t}$ and $d w_{t}$. Substitution in the forex order flow constraint (4) implies that the exchange rate process can be represented as:

$$
d E_{t}=k_{1} \Delta_{t}+k_{2}\left(E_{t}-\bar{E}\right)+k_{3} d w_{t}
$$

The whole model is therefore amenable to equation (5) of the paper (proposition 3 ). 


\section{C2. Identification of the Parameters}

Market clearing in the two stock markets $\left(K_{t}^{h}+K_{t}^{h *}=1, K_{t}^{f}+K_{t}^{f *}=1\right)$ implies 4 parameter constraints (one for each element in $\boldsymbol{\Psi}_{t}^{j}=\left(1, D^{j}, \Delta_{t}, \Lambda_{t}\right)^{T}$ ) given by

$$
\begin{aligned}
p_{0} & =\frac{-\rho \operatorname{det} \Omega-\mathcal{E}_{t}\left(d E_{t} d P_{t}^{f}\right)\left(-\Omega_{12}+\Omega_{11}\right)}{r\left(\Omega_{11}-2 \Omega_{12}+\Omega_{22}\right)} \\
p_{F} & =1 \\
p_{\Delta} & =-e_{\Delta} \frac{m_{\alpha}\left(\Omega_{21}+\Omega_{11}\right)}{\left(\alpha_{D}+r\right) \bar{\Omega}} \\
p_{\Lambda} & =-e_{\Lambda} \frac{m_{z}\left(\Omega_{21}+\Omega_{11}\right)}{(-z+r) \bar{\Omega}}
\end{aligned}
$$

where we define $\bar{\Omega}=\Omega_{11}+2 \Omega_{21}+\Omega_{22}$. The forex order flow constraint (4) implies an additional 3 constraints (for $\Delta_{t}, \Lambda_{t}, d w_{t}$ ) given by

$$
\begin{aligned}
e_{\Delta}\left(\overline{K D}-\kappa \alpha_{D}\right)+m_{\Delta} \frac{1}{\rho}\left(\bar{D}+\alpha_{D} \bar{P}\right) & =-\bar{K} \\
e_{\Lambda}(\overline{K D}+\kappa z)+m_{\Lambda} \frac{1}{\rho}(\bar{D}-z \bar{P}) & =0 \\
e_{\Delta} \kappa \sigma_{D}+e_{\Lambda} \kappa-m_{\Delta} \frac{1}{\rho} \bar{P} \sigma_{D}-m_{\Lambda} \frac{1}{\rho} \bar{P} & =0 .
\end{aligned}
$$

These 7 equations determine the 7 parameters $p_{0}, p_{F}, p_{\Delta}, p_{\Lambda}, e_{\Delta}, e_{\Lambda}, z$ as a function of $\bar{P}, \bar{\Lambda}$ and $\bar{K}$ as well as the parameters of the dividend process $\left(\alpha_{D}, \bar{D}, \sigma_{D}\right)$, the elasticity of the forex liquidity supply, $\kappa$, and the investor risk aversion $\rho$. Moreover, steady state levels $\bar{P}>0, \bar{\Lambda}$ and $0<\bar{K}<1$ are equal to:

$$
\begin{aligned}
\bar{P} & =p_{0}+\frac{\bar{D}}{r}+p_{\Lambda} \bar{\Lambda}=p_{0}+\frac{\bar{D}}{r} \\
\bar{K} & =\frac{\rho\left[\Omega_{11}-\Omega_{21}\right]-\mathcal{E}_{t}\left(d E_{t} d P_{t}^{f}\right)}{\rho\left(\Omega_{11}-2 \Omega_{21}+\Omega_{22}\right)} \\
\bar{\Lambda} & =0 .
\end{aligned}
$$

The covariances are given by

$$
\begin{aligned}
& \Omega_{11}=\left(f_{D} \sigma_{D}\right)^{2}+2\left[p_{\Delta} \sigma_{D}+p_{\Lambda}\right]^{2}+2 f_{D} \sigma_{D}\left[p_{\Delta} \sigma_{D}+p_{\Lambda}\right] \\
& \Omega_{12}=-2\left(p_{\Delta} \sigma_{D}+p_{\Lambda}\right)^{2}-\left[2\left(p_{\Delta} \sigma_{D}+p_{\Lambda}\right)+f_{D} \sigma_{D}\right] \bar{P}\left(e_{\Delta} \sigma_{D}+e_{\Lambda}\right)-2\left(p_{\Delta} \sigma_{D}+p_{\Lambda}\right) f_{D} \sigma_{D} \\
& \Omega_{22}=\left(f_{D} \sigma_{D}\right)^{2}+2\left[\bar{P}\left(e_{\Delta} \sigma_{D}+e_{\Lambda}\right)+p_{\Delta} \sigma_{D}+p_{\Lambda}\right]^{2}+2 f_{D} \sigma_{D}\left[\bar{P}\left(e_{\Delta} \sigma_{D}+e_{\Lambda}\right)+p_{\Delta} \sigma_{D}+p_{\Lambda}\right]
\end{aligned}
$$

and furthermore

$$
\bar{\Omega}=2\left(f_{D} \sigma_{D}\right)^{2}+2\left[\bar{P}\left(e_{\Delta} \sigma_{D}+e_{\Lambda}\right)\right]^{2},
$$

where $\bar{\Omega}(z)=\Omega_{11}+2 \Omega_{21}+\Omega_{22}>0$ represents the instantaneous excess pay-off variance of the total market portfolio of all domestic and foreign equity. 


\section{C3. Existence and Uniqueness of Parameter z}

Combining equations (12), (10) and the definition of $\bar{\Omega}(z)$ we obtain an expression which characterizes the root $z$ of the system as

$$
\frac{\rho}{2}(\overline{K D}+\kappa z) \bar{\Omega}=f(z)
$$

for a function $f(z)=[(-z+r) \bar{P}-\bar{D}](\bar{D}-z \bar{P})$.

The function $f(z)$ represents a convex parabola. It has two intersects with the x-axes at $z_{1}=$ $-\bar{D} / \bar{P}+r \leq 0$ and $z_{2}=\bar{D} / \bar{P} \geq 0$. Since $\frac{\rho}{2}(\overline{K D}+\kappa z) \bar{\Omega}$ is upward sloping $(d \bar{\Omega} / d z>0)$, and positive for $z=0$, it intersects the parabola at least once and at most twice. The first intersection is negative and the second one, if it exists, is positive (and therefore discarded for stability reasons). Hence there always exists a unique value $z<0$ such that the solution is stable.

\section{C4. Existence and Uniqueness of Parameters $\mathrm{p}_{0}, \mathrm{p}_{\Delta}, \mathrm{p}_{\Lambda}, \mathrm{e}_{\Delta}, \mathrm{e}_{\Lambda}$}

\section{Proposition 4 (Existence and Uniqueness of the Incomplete Market Equilibrium):}

We now have to prove that for such a solution $z$, the parameters $p_{0}, p_{\Delta}, p_{\Lambda}, e_{\Delta}, e_{\Lambda}$ exist and are uniquely defined. We first derive useful intermediate results for $e_{\Delta}$ and $p_{\Delta}$.

Assume that the forex supply is sufficiently price elastic with $\kappa>\bar{\kappa}=\overline{K D P} /(\bar{D}-r \bar{P})=\overline{K D P} /\left(-r p_{0}\right)$. Then $\frac{\rho}{2}(\overline{K D}+\kappa z) \bar{\Omega}(z)$ intersects the $\mathrm{x}$-axis to the right of $z_{1}=-\bar{D} / \bar{P}+r$ and the root $z$ is confined to the interval $z \in[-\bar{D} / \bar{P}+r,-\overline{K D} / \kappa]$. This implies $(-z+r) \bar{P}-\bar{D}<0$. Moreover, we require that $-\alpha_{D}<-\bar{D} / \bar{P}+r$ or $\left(\alpha_{D}+r\right) \bar{P}-\bar{D}>0$. The latter condition can be rewritten as $\alpha_{D} \bar{P}>-r p_{0}$, where $p_{0}$ represents the risk discount on the asset price. We can make $p_{0}$ sufficiently close to zero by setting an upper threshold value for the investor risk aversion, hence requiring $\bar{\rho}_{1}>\rho$. It is then easy to show that for any $\rho<\bar{\rho}_{1}$ and $\kappa>\bar{\kappa}$, we have $e_{\Delta}<0$ and $p_{\Delta}>0$. It also follows using equation (11) that $m_{\Delta}<0$.

Equation (15) can be rewritten as:

$$
\bar{\Omega}=2\left(f_{D} \sigma_{D}\right)^{2}+2\left[\bar{P}\left(e_{\Delta} \sigma_{D}+e_{\Lambda}\right)\right]^{2}=\frac{[(-z+r) \bar{P}-\bar{D}](\bar{D}-z \bar{P})}{\frac{\rho}{2}(\overline{K D}+\kappa z)}>0
$$

A necessary condition for the existence of a real solution for $\bar{e} \equiv e_{\Delta} \sigma_{D}+e_{\Lambda}$ is

$$
V(\rho, \kappa)=\frac{[(-z+r) \bar{P}-\bar{D}](\bar{D}-z \bar{P})}{\rho(\overline{K D}+\kappa z)}-\left(f_{D} \sigma_{D}\right)^{2} \geq 0 .
$$

This condition is satisfied only if $\rho\left(f_{D} \sigma_{D}\right)^{2}$ is sufficiently small or risk aversion is below a certain threshold $\rho<\bar{\rho}_{2}$. We now take $\rho<\min \left(\bar{\rho}_{1}, \bar{\rho}_{2}\right)=\bar{\rho}$. It is possible to show that $\bar{e} \equiv e_{\Delta} \sigma_{D}+e_{\Lambda}<0$ (see Appendix $\mathrm{E}$, corollary 2). Therefore we can rewrite equation (15) in linear form as

$$
e_{\Delta} \sigma_{D}+e_{\Lambda}=-\frac{1}{\bar{P}} \sqrt{V(\rho, \kappa)}
$$

We define a vector $\mathbf{e}=\left(e_{\Delta}, e_{\Lambda}, m_{\Delta}, m_{\Lambda}\right)^{T}$ and matrices

$$
\mathbf{A}=\left(\begin{array}{cccc}
\sigma_{D} & 1 & 0 & 0 \\
\left(\overline{K D}-\kappa \alpha_{D}\right) & 0 & \frac{1}{\rho}\left(\bar{D}+\alpha_{D} \bar{P}\right) & 0 \\
0 & (\overline{K D}+\kappa z) & 0 & \frac{1}{\rho}(\bar{D}-z \bar{P}) \\
\kappa \sigma_{D} & \kappa & -\frac{1}{\rho} \bar{P} \sigma_{D} & -\frac{1}{\rho} \bar{P}
\end{array}\right) \quad \mathbf{b}=\left(\begin{array}{c}
-\frac{1}{\bar{P}} \sqrt{V(\rho, \kappa)} \\
-\bar{K} \\
0 \\
0
\end{array}\right)
$$


so that the linear system $\mathbf{A e}=\mathbf{b}$ summarizes the 4 equations (11), (12), (13) and (16). We check that $\operatorname{det}(\mathbf{A}) \neq 0$ in general. Hence there exists a unique solution for $\mathbf{e}$ given by $\mathbf{e}=\mathbf{A}^{-1} \mathbf{b}$.

We now show that this implies a unique solution for the price coefficients $\mathbf{p}=\left(p_{\Delta}, p_{\Lambda}\right)^{T}$. Note that

$$
\Omega_{11}+\Omega_{12}=\left(f_{D} \sigma_{D}\right)^{2}-\left[2\left(p_{\Delta} \sigma_{D}+p_{\Lambda} \sigma_{\Lambda}\right)+f_{D} \sigma_{D}\right] \bar{P}\left(e_{\Delta} \sigma_{D}+e_{\Lambda}\right)
$$

is linear in $\mathbf{p}$ for a fixed vector $\mathbf{e}$. The equations (9) and (10) are therefore of the form $\mathbf{C p}=\mathbf{d}$, where we define

$$
\mathbf{C}=2 \bar{P}\left(e_{\Delta} \sigma_{D}+e_{\Lambda}\right)\left(\begin{array}{cc}
c_{\Delta} \sigma_{D} & c_{\Delta} \\
c_{\Lambda} \sigma_{D} & c_{\Lambda}
\end{array}\right)-\left(\begin{array}{cc}
1 & 0 \\
0 & 1
\end{array}\right), \quad \mathbf{d}=d_{0}\left(\begin{array}{c}
c_{\Delta} \\
c_{\Lambda}
\end{array}\right)
$$

with $d_{0}=\left(f_{D} \sigma_{D}\right)^{2}-f_{D} \sigma_{D} \bar{P}\left(e_{\Delta} \sigma_{D}+e_{\Lambda}\right)$, and additional parameters

$$
c_{\Delta}=\frac{e_{\Delta}\left[\left(\alpha_{D}+r\right) \bar{P}-\bar{D}\right]}{\left(\alpha_{D}+r\right) \bar{\Omega}}, \quad c_{\Lambda}=\frac{e_{\Lambda}[(-z+r) \bar{P}-\bar{D}]}{(-z+r) \bar{\Omega}} .
$$

We check that $\operatorname{det}(\mathbf{C}) \neq 0$ in general. We can therefore invert $\mathbf{C}$ and obtain a unique solution for p. Finally, the coefficient $p_{0}<0$ is uniquely determined by equation (7) and $e_{\Delta}$ and $e_{\Lambda}$ are uniquely determined by (11) and (12). Hence the uniqueness of the incomplete market equilibrium for all $\rho<\bar{\rho}$ and $\kappa>\bar{\kappa}$ (proposition 4 ).

\section{Appendix D: Infinitely Elastic Supply and Complete Risk Shar- ing}

\section{Proposition 5:}

For a completely price elastic currency supply $(\kappa \rightarrow \infty)$, the exchange rate is constant at $\bar{E}=1$. This requires that $e_{\Delta}=e_{\Lambda}=0$. It follows that $c_{\Delta}=c_{\Lambda}=0$ and $\mathbf{C p}=\mathbf{d}$ implies $p_{\Delta}=p_{\Lambda}=0$. The latter implies $m_{\Delta}=m_{\Lambda}=0$. Moreover, since $\mathcal{E}_{t}\left(d E_{t} d P_{t}^{f}\right)=0$, and $\Omega_{21}=0$, we obtain steady state equity holdings

$$
\bar{K}=\frac{\left[\Omega_{11}\right]}{\left(\Omega_{11}+\Omega_{22}\right)}=\frac{1}{2},
$$

which correspond to full equity risk sharing as in proposition 2 .

\section{Appendix E: Correlation Structure}

\section{Corollary 1:}

The symmetry of the model implies $\mathcal{E}_{t}\left(d E_{t} d R_{t}^{h}\right)=-\mathcal{E}_{t}\left(d E_{t} d R_{t}^{f *}\right)$. Furthermore,

$$
\mathcal{E}_{t}\left(d E_{t} d R_{t}^{h}\right) d t=\left(e_{\Delta} \sigma_{D}+e_{\Lambda}\right)\left[f_{D} \sigma_{D}+2\left(p_{\Delta} \sigma_{D}+p_{\Lambda}\right)\right]<0
$$

amounts to showing that $\bar{e} \equiv e_{\Delta} \sigma_{D}+e_{\Lambda}<0$ and $f_{D} \sigma_{D}+2\left(p_{\Delta} \sigma_{D}+p_{\Lambda}\right)>0$. We note that the latter follows for some $\kappa>\bar{\kappa}$ since $p_{\Delta} \sigma_{D}+p_{\Lambda} \rightarrow 0$ for $\kappa \rightarrow \infty$ (see proposition 5) and $f_{D} \sigma_{D}>0$. To simplify notations we define

$$
m=\frac{\left(\overline{K D}-\alpha_{D} \kappa\right) \bar{P}}{\left(\bar{D}+\alpha_{D} \bar{P}\right)}, \quad n=\frac{(\overline{K D}+z \kappa) \bar{P}}{(\bar{D}-z \bar{P})} .
$$


Clearly, $m<0$ and $n<0$ under the parameter constraints of proposition 4 . Moreover, $m-n<0$, because (for $\alpha_{D}>-z$ ) we find

$$
(\bar{D}-z \bar{P})\left(\overline{K D}-\alpha_{D} \kappa\right)-\left(\bar{D}+\alpha_{D} \bar{P}\right)(\overline{K D}+z \kappa)=-\left(\alpha_{D}+z\right)[\bar{D} \kappa+\overline{P K D}]<0
$$

Substituting equations (11) and (12) into (13) implies

$$
e_{\Delta} \sigma_{D}[\kappa+m]+e_{\Lambda}[\kappa+n]=\frac{-\overline{K P} \sigma_{D}}{\left(\bar{D}+\alpha_{D} \bar{P}\right)}<0 .
$$

Subtracting the term $e_{\Delta} \sigma_{D}(m-n)>0$ (because $e_{\Delta}<0$ ) from the left hand side implies $e_{\Delta} \sigma_{D}[\kappa+n]+$ $e_{\Lambda}[\kappa+n]<0$. Therefore

$$
e_{\Delta} \sigma_{D}+e_{\Lambda}<0
$$

since $\kappa+n>0$ is trivially fulfilled (for $\kappa>\bar{\kappa}, \bar{K}>0, \bar{D}>0, \bar{P}>0$ ). Hence $\mathcal{E}_{t}\left(d E_{t} d R_{t}^{h}\right)<0$.

\section{Corollary 2:}

The home and foreign excess pay-off processes (in local currency) and the exchange rate returns are

$$
\begin{aligned}
d R_{t}^{h} & =\alpha_{0}^{h} d t+\alpha_{D}^{h} D_{t}^{h} d t+\alpha_{\Delta}^{h} \Delta_{t} d t+\alpha_{\Lambda}^{h} \Lambda_{t} d t+p_{F} f_{D} \sigma_{D} d w_{t}^{h}+\left(p_{\Delta} \sigma_{D}+p_{\Lambda}\right) d w_{t} \\
d R_{t}^{f *} & =\alpha_{0}^{f *} d t+\alpha_{D}^{f *} D_{t}^{f} d t+\alpha_{\Delta}^{f *} \Delta_{t} d t+\alpha_{\Lambda}^{f *} \Lambda_{t} d t+p_{F} f_{D} \sigma_{D} d w_{t}^{f}-\left(p_{\Delta} \sigma_{D}+p_{\Lambda}\right) d w_{t} \\
d E_{t} & =-e_{\Delta} \alpha_{D} \Delta_{t} d t-e_{\Lambda} \alpha_{D} \Lambda_{t} d t+\left(e_{\Delta} \sigma_{D}+e_{\Lambda}\right) d w_{t}
\end{aligned}
$$

and the relative payoff follows as

$$
d R_{t}^{f *}-d R_{t}^{h}=2 p_{\Delta}\left(\alpha_{D}+r\right) \Delta_{t} d t+2 p_{\Lambda}(-z+r) \Lambda_{t} d t-\left[f_{D} \sigma_{D}+2 p_{\Delta} \sigma_{D}+2 p_{\Lambda}\right] d w_{t}
$$

Hence, we obtain a perfect negative return correlation,

$$
-\operatorname{Corr}\left[d E_{t},\left(d R_{t}^{f *}-d R_{t}^{h}\right) / \bar{P}\right]=-1<0 .
$$

\section{Corollary 3:}

The net foreign equity inflows are given by

$$
\begin{gathered}
d K_{t}^{f}-d K_{t}^{h *}=\frac{1}{\rho}\left[\alpha_{D} m_{\Delta} \Delta_{t} d t-z m_{\Lambda} \Lambda_{t} d t\right]-\frac{1}{\rho}\left[m_{\Delta} \sigma_{D}+m_{\Lambda} \sigma_{\Lambda}\right] d w_{t} . \\
\mathcal{E}_{t}\left(d E_{t}, d K_{t}^{f}-d K_{t}^{h *}\right)=-\frac{2 \kappa}{\bar{P}}\left(e_{\Delta} \sigma_{D}+e_{\Lambda}\right)^{2} d t
\end{gathered}
$$

Hence

$$
-\operatorname{Corr}\left[d E_{t},\left(d K_{t}^{f}-d K_{t}^{h *}\right)\right]=1>0
$$

\section{Appendix F: Binding Short-Sale Constraint}

Define $\mathbf{x}_{t}=\left(x^{h}, x^{f}, x^{b}\right)$ as the $(1 \times 3)$ vector of holdings in home equity, foreign equity, and foreign bonds, respectively. Denote by $\mathbf{d R}_{t}=\left(d R^{h}, d R^{f}, d R^{b}\right)$ the corresponding $(1 \times 3)$ excess pay-off vector. $\mathcal{E}\left(d R_{t}^{h}\right), \mathcal{E}\left(d R_{t}^{f}\right)$ are given in Appendix $\mathrm{C}$ and $\mathcal{E}\left(d R_{t}^{b}\right) \approx-\bar{P} d E_{t}$. We call $\boldsymbol{\Sigma}=\mathcal{E}\left(\mathbf{d R}_{t}^{T} \mathbf{d R}_{t}\right)$ the $(3 \times 3)$ 
covariance matrix of the excess payoffs. We show that the unconstrained maximization produces an interior solution with $x^{b}<0$. This implies that the short sale constraint on foreign riskless bonds is always binding in equilibrium.

$$
\boldsymbol{\Sigma}=\mathcal{E}\left(\mathbf{d R}_{t}^{T} \mathbf{d R}_{t}\right)=\left(\begin{array}{ccc}
\sigma_{p p} & -\bar{P} \sigma_{p e}+\sigma_{f h} & -\bar{P} \sigma_{p e} \\
-\bar{P} \sigma_{p e}+\sigma_{f h} & \bar{P}^{2} \sigma_{e e}+2 \bar{P} \sigma_{p e}+\sigma_{p p} & \bar{P}^{2} \sigma_{e e}+\bar{P} \sigma_{p e} \\
-\bar{P} \sigma_{p e} & \bar{P}^{2} \sigma_{e e}+\bar{P} \sigma_{p e} & \bar{P}^{2} \sigma_{e e}
\end{array}\right) d t
$$

where we define $\mathcal{E}\left(d R_{t}^{h} d R_{t}^{h}\right)=\sigma_{p p} d t, \mathcal{E}\left(d E_{t} d R_{t}^{h}\right)=\sigma_{p e} d t, \mathcal{E}\left(d R_{t}^{f} d R_{t}^{h}\right)=\sigma_{f h} d t$ and $\mathcal{E}\left(d E_{t} d E_{t}\right)=\sigma_{e e} d t$. Inverting the symmetric covariance matrix allows us to compute the optimal unconstrained portfolio holdings $\mathbf{x}_{t}=\left(x^{h}, x^{f}, x^{b}\right)$.

In particular for symmetric steady state holdings $\mathbf{x}_{t}=\left(1-\bar{K}, \bar{K}, \bar{x}^{b}\right)$ we obtain

$$
\begin{aligned}
\rho \operatorname{det} \boldsymbol{\Sigma}= & {\left[-\bar{P}^{2} \sigma_{e e} \sigma_{f h}-2 \bar{P}^{2} \sigma_{p e}^{2}+\bar{P}^{2} \sigma_{e e} \sigma_{p p}\right](\bar{D}-r \bar{P}) d t+\left[\bar{P}^{2} \sigma_{e e} \sigma_{p p}-\bar{P}^{2} \sigma_{p e}^{2}\right] \bar{P} \sigma_{p e} d t } \\
\rho \bar{x}^{b} \operatorname{det} \boldsymbol{\Sigma}= & {\left[\bar{P}^{2} \sigma_{f h} \sigma_{e e}+2 \bar{P}^{2} \sigma_{p e}^{2}-\bar{P}^{2} \sigma_{p p} \sigma_{e e}\right](\bar{D}-r \bar{P}) d t } \\
& +\left[-\bar{P}^{2} \sigma_{p p} \sigma_{e e}-\bar{P} \sigma_{p e} \sigma_{p p}+\bar{P}^{2} \sigma_{p e}^{2}-\bar{P} \sigma_{f h} \sigma_{p e}\right] \bar{P} \sigma_{p e} d t .
\end{aligned}
$$

and taking the sum $\left(\sigma_{p p}+\sigma_{f h}>0\right)$ implies :

$$
\rho\left(\bar{K}+\bar{x}^{b}\right) \operatorname{det} \boldsymbol{\Sigma}=-\left(\sigma_{p p}+\sigma_{f h}\right) \bar{P}^{2} \sigma_{p e}^{2} d t<0 .
$$

Since $\boldsymbol{\Sigma}$ is positive semi-definite, $\rho \bar{K} \operatorname{det} \boldsymbol{\Sigma} \geq 0$. It follows that $\bar{x}^{b}<0$. Hence, the constraint $\bar{x}^{b} \geq 0$ is in fact binding and investors hold zero foreign bonds in the steady state. 
Table 1:

Volatility Ratios of Exchange Rate and Stock Market Index Returns

Reported are volatility ratios of daily (log) exchange rate returns and daily (log) foreign stock market index returns (in local currency) for various sample periods. The exchange rate $E_{t}$ is expressed in foreign currency per dollar ( $d E_{t}>0$ corresponds to a dollar appreciation), and the index $f$ represents one of the 17 foreign OECD countries. The last row provides the result for the pooled data.

\begin{tabular}{lrrr}
\hline \hline & & & \\
& & $\sqrt{\frac{\operatorname{Var}\left(d E_{t}\right)}{\operatorname{Var}\left(d R_{t}^{f *} / \bar{P}\right)}}$ & \\
& & & \\
\cline { 2 - 3 } & \multicolumn{1}{c}{$1 / 1 / 80-12 / 31 / 01$} & $(\mathrm{a})$ & $(\mathrm{c})$ \\
& 0.5850 & 0.6494 & 0.7070 \\
Australia & 0.8205 & 0.6272 & 0.6270 \\
Austria & 0.8386 & 0.8053 & 0.6770 \\
Belgium-Luxembourg & 0.6951 & 0.6351 & 0.5540 \\
Denmark & 0.3690 & 0.3388 & 0.2472 \\
Finland & 0.6081 & 0.5450 & 0.4785 \\
France & 0.6211 & 0.5537 & 0.4721 \\
Germany & 0.5968 & 0.5921 & 0.5361 \\
Ireland & 0.4901 & 0.4688 & 0.4198 \\
Italy & 0.6279 & 0.5444 & 0.5855 \\
Japan & 0.6555 & 0.6553 & 0.5196 \\
Netherlands & 0.4517 & 0.4937 & 0.5023 \\
Norway & 0.6423 & 0.6530 & 0.5980 \\
Portugal & 0.5920 & 0.5156 & 0.4478 \\
Spain & 0.4664 & 0.4424 & 0.3766 \\
Sweden & 0.8450 & 0.7241 & 0.6441 \\
U.K. & 0.6599 & 0.6037 & 0.4747 \\
Mean & & & \\
Std. Dev. & 0.6215 & 0.5793 & 0.1159 \\
Pooled Data & & & \\
& 0.1328 & & \\
\hline \hline
\end{tabular}


Table 2:

Daily Correlations of Exchange Rate and Foreign Stock Market Excess Returns

Reported are correlations of daily (log) exchange rate returns, $-d E_{t}$, and the daily (log) foreign stock market index returns (in local currency) relative to the U.S. market index return (in dollars), $\left(d R_{t}^{f *}-\right.$ $\left.d R_{t}^{h}\right) / \bar{P}$, for various sample periods. The exchange rate $E_{t}$ is expressed in foreign currency per dollar $\left(d E_{t}>0\right.$ corresponds to a dollar appreciation). The index $f$ represents one of 17 OECD countries and $h$ the U.S. market. The model predicts $-\operatorname{Corr}\left(d E_{t},\left(d R_{t}^{f *}-d R_{t}^{h}\right) / \bar{P}\right)<0$. We test if the correlation is significantly different from zero using robust standard errors and denote by ${ }^{*},{ }^{* *}$ and ${ }^{* * *}$ significance at a 10, 5 and 1 percent level, respectively. The last row provides the result for the pooled data.

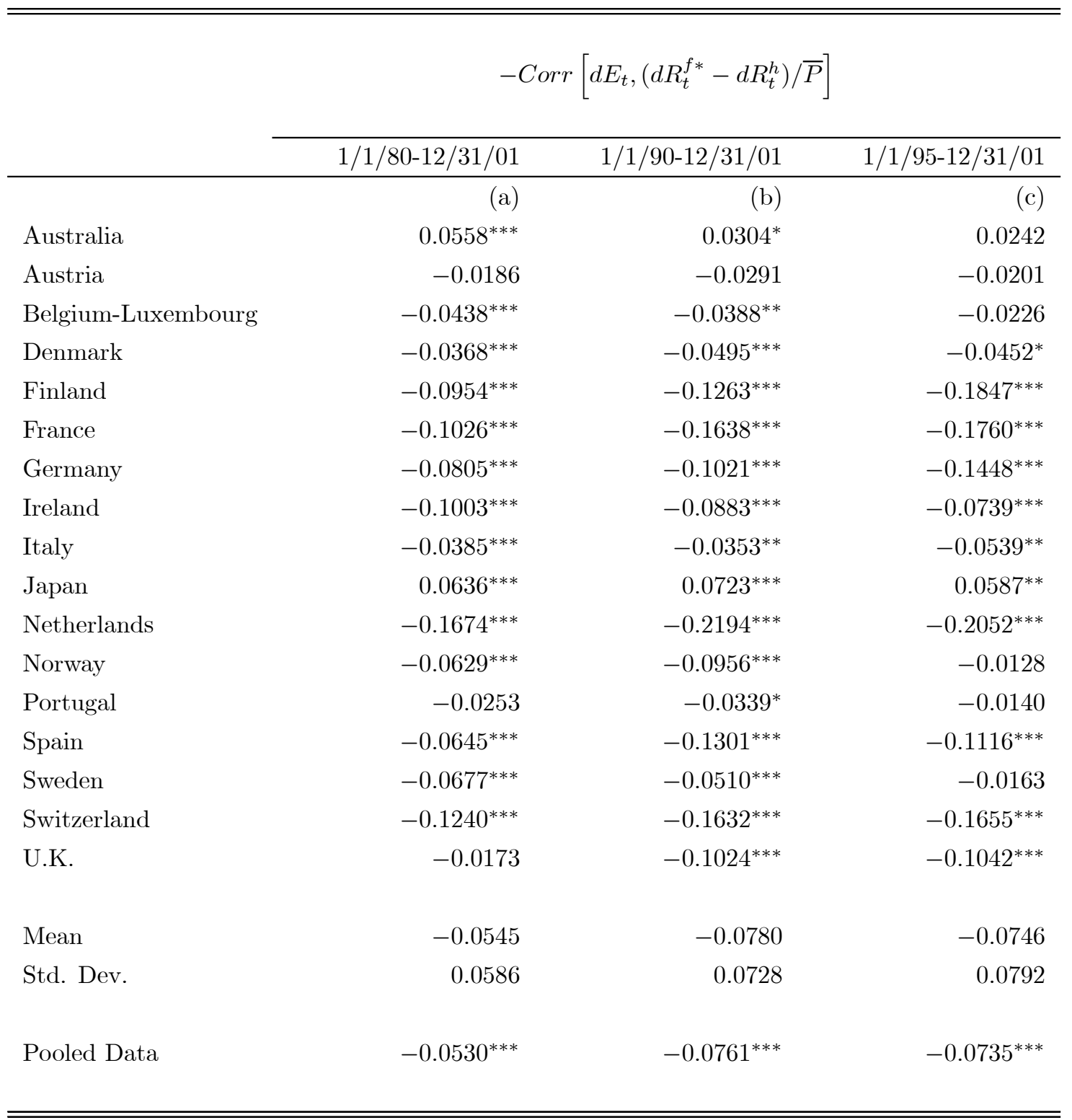


Table 3:

Monthly Correlations of Exchange Rate and Foreign Stock Market Excess Returns

Reported are correlations of monthly $(\log )$ exchange rate returns, $-d E_{t}$, and the daily (log) foreign stock market index returns (in local currency) relative to the U.S. market index return (in dollars), $\left(d R_{t}^{f *}-d R_{t}^{h}\right) / \bar{P}$, for various sample periods. The exchange rate $E_{t}$ is expressed in foreign currency per dollar $\left(d E_{t}>0\right.$ corresponds to a dollar appreciation). The index $f$ represents one of 17 foreign OECD countries and $h$ the U.S. market. The model predicts $-\operatorname{Corr}\left[d E_{t},\left(d R_{t}^{f *}-d R_{t}^{h}\right) / \bar{P}\right]<0$. We test if the correlation is significantly different from zero using robust standard errors and denote by ${ }^{* * *}$ and ${ }^{* * *}$ significance at a 10, 5 and 1 percent level, respectively. The last row provides the result for the pooled data.

\begin{tabular}{|c|c|c|c|}
\hline & \multicolumn{3}{|c|}{$-\operatorname{Corr}\left[d E_{t},\left(d R_{t}^{f *}-d R_{t}^{h}\right) / \bar{P}\right]$} \\
\hline & $1 / 80-12 / 01$ & $1 / 90-12 / 01$ & $1 / 95-12 / 01$ \\
\hline & (a) & (b) & $(\mathrm{c})$ \\
\hline Australia & $0.1796^{* * *}$ & 0.0102 & -0.1415 \\
\hline Austria & -0.1020 & $-0.1998^{* *}$ & -0.1507 \\
\hline Belgium-Luxembourg & $-0.2508^{* * *}$ & $-0.2569^{* * *}$ & -0.1352 \\
\hline Denmark & $-0.2179^{* * *}$ & $-0.2934^{* * *}$ & $-0.3358^{* * *}$ \\
\hline Finland & $-0.1580^{* *}$ & $-0.2570^{* * *}$ & $-0.1794^{* *}$ \\
\hline France & $-0.1230^{* *}$ & $-0.3473^{* * *}$ & $-0.3118^{* * *}$ \\
\hline Germany & $-0.1409^{* *}$ & $-0.2871^{* * *}$ & $-0.3679^{* * *}$ \\
\hline Ireland & $-0.2710^{* * *}$ & $-0.2805^{* * *}$ & $-0.2996^{* * *}$ \\
\hline Italy & $-0.1308^{* *}$ & -0.1312 & $-0.1755^{* *}$ \\
\hline Japan & 0.6590 & -0.0276 & $-0.2810^{* * *}$ \\
\hline Netherlands & $-0.3403^{* * *}$ & $-0.3689^{* * *}$ & $-0.3059^{* * *}$ \\
\hline Norway & -0.0936 & $-0.1787^{* *}$ & -0.0264 \\
\hline Portugal & -0.0763 & $-0.1341^{*}$ & -0.0669 \\
\hline Spain & $-0.1250^{* *}$ & $-0.2183^{* * *}$ & $-0.2090^{* *}$ \\
\hline Sweden & $-0.2287^{* * *}$ & $-0.2862^{* * *}$ & -0.0930 \\
\hline Switzerland & $-0.1761^{* * *}$ & $-0.2318^{* * *}$ & -0.1376 \\
\hline U.K. & $-0.1187^{*}$ & $-0.2778^{* * *}$ & $-0.2530^{* * *}$ \\
\hline Mean & -0.1009 & -0.2169 & -0.2041 \\
\hline Std. Dev. & 0.2248 & 0.1059 & 0.1012 \\
\hline Pooled Data & $-0.1232^{* * *}$ & $-0.2119^{* * *}$ & $-0.1901^{* * *}$ \\
\hline
\end{tabular}


Table 4:

Regressions of Quarterly Exchange Rate on Foreign Stock Market Excess Returns

Reported are regressions of quarterly (log) exchange rate returns on the quarterly (log) foreign stock market excess return (in local currency) relative to the U.S. stock market return (in dollars) for the period 1990-2002:

$$
-d E_{t}=\alpha+\beta \times\left(d R_{t}^{f *}-d R_{t}^{h}\right) / \bar{P}+\epsilon_{t} .
$$

The exchange rate $E_{t}$ is expressed in foreign currency per dollar $\left(d E_{t}>0\right.$ corresponds to a dollar appreciation). The index $f$ represents one of 17 foreign OECD countries and $h$ the U.S. market. The model predicts $\beta<0$. We denote by ${ }^{*},{ }^{* *}$ and ${ }^{* * *}$ significance at a 10,5 and 1 percent level, respectively. Newey West adjusted standard errors are reported in parentheses. The last row provides the result for the pooled data.

\begin{tabular}{|c|c|c|c|c|c|}
\hline & \multicolumn{4}{|c|}{ Coefficients (1/90-12/01) } & \multirow[b]{2}{*}{$\operatorname{Adj~} R^{2}$} \\
\hline & $\alpha$ & & $\beta$ & & \\
\hline Australia & -0.0092 & $(0.0064)$ & -0.1124 & $(0.1336)$ & 0.0215 \\
\hline Austria & -0.0113 & $(0.0078)$ & $-0.2046^{* *}$ & $(0.0825)$ & 0.1535 \\
\hline Belgium-Luxembourg & -0.0078 & $(0.0073)$ & $-0.2613^{*}$ & $(0.1430)$ & 0.0659 \\
\hline Denmark & -0.0065 & $(0.0067)$ & $-0.3266^{* * *}$ & $(0.0780)$ & 0.2294 \\
\hline Finland & -0.0089 & $(0.0087)$ & -0.0734 & $(0.0451)$ & 0.0340 \\
\hline France & -0.0068 & $(0.0065)$ & $-0.3999^{* * *}$ & $(0.0783)$ & 0.2447 \\
\hline Germany & -0.0080 & $(0.0068)$ & $-0.3385^{* * *}$ & $(0.0656)$ & 0.2467 \\
\hline Ireland & -0.0090 & $(0.0069)$ & $-0.3372^{* * *}$ & $(0.0604)$ & 0.2646 \\
\hline Italy & -0.0126 & $(0.0081)$ & -0.1423 & $(0.0972)$ & 0.0462 \\
\hline Japan & -0.0004 & $(0.0119)$ & -0.0530 & $(0.1483)$ & 0.0151 \\
\hline Netherlands & -0.0052 & $(0.0066)$ & $-0.5273^{* * *}$ & $(0.1121)$ & 0.2677 \\
\hline Norway & -0.0091 & $(0.0070)$ & $-0.1646^{* * *}$ & $(0.0562)$ & 0.0998 \\
\hline Portugal & -0.0116 & $(0.0069)$ & $-0.1831^{* *}$ & $(0.0740)$ & 0.1226 \\
\hline Spain & -0.0113 & $(0.0063)$ & $-0.2847^{* * *}$ & $(0.0659)$ & 0.3029 \\
\hline Sweden & -0.0095 & $(0.0082)$ & $-0.2698^{* * *}$ & $(0.0969)$ & 0.2809 \\
\hline Switzerland & -0.0009 & $(0.0083)$ & $-0.3368^{* *}$ & $(0.1377)$ & 0.1305 \\
\hline U.K. & -0.0045 & $(0.0073)$ & $-0.2738^{* *}$ & $(0.1348)$ & 0.0587 \\
\hline Mean & -0.0083 & $(0.0075)$ & -0.2523 & $(0.0947)$ & 0.1477 \\
\hline Std. Dev. & 0.0030 & $(0.0014)$ & 0.1237 & $(0.0339)$ & 0.1096 \\
\hline Pooled Data & -0.0081 & $(0.0057)$ & $-0.2083^{* * *}$ & $(0.0426)$ & 0.1261 \\
\hline
\end{tabular}


Table 5:

\section{Correlation of Exchange Rate Returns and Net Foreign Equity Inflows}

Reported are correlations of the exchange rate return, $-d E_{t}$, and net foreign stock ownership increase by U.S. residents, $d K_{t}^{f}-d K_{t}^{h *}$, for various sample periods. Net foreign stock ownership increase (or net foreign inflow) is defined as net U.S. purchases of foreign equities minus net foreign purchases of U.S. equities, and normalized as a proportion of the average absolute level of net foreign stock ownership increase by U.S. residents over the previous twelve months. The theory predicts $-\operatorname{Corr}\left(d E_{t}, d K_{t}^{f}-\right.$ $\left.d K_{t}^{h *}\right)>0$. We test if the correlation is significantly different from zero using robust standard errors and denote by ${ }^{*},{ }^{* *}$ and ${ }^{* * *}$ significance at a 10,5 and 1 percent level, respectively. The last row provides the result for the pooled data.

\begin{tabular}{|c|c|c|c|}
\hline & \multicolumn{3}{|c|}{$-\operatorname{Corr}\left(d E_{t}, d K_{t}^{f}-d K_{t}^{h *}\right)$} \\
\hline & $1 / 80-12 / 01$ & $1 / 90-12 / 01$ & $1 / 95-12 / 01$ \\
\hline & (a) & (b) & $(\mathrm{c})$ \\
\hline Australia & 0.0112 & -0.0478 & -0.0010 \\
\hline Austria & $-0.1155^{* * *}$ & $0.2051^{* * *}$ & $0.2740^{* * *}$ \\
\hline Belgium-Luxembourg & 0.1208 & $0.2541^{* * *}$ & $0.3846^{* * *}$ \\
\hline Denmark & $-0.0938^{* *}$ & -0.0174 & -0.0295 \\
\hline Finland & -0.0002 & -0.0194 & 0.0473 \\
\hline France & $0.1400^{* *}$ & $0.1539^{* *}$ & $0.1814^{* *}$ \\
\hline Germany & -0.0872 & -0.0412 & 0.1210 \\
\hline Ireland & 0.0445 & 0.1461 & 0.0769 \\
\hline Italy & -0.0071 & 0.0824 & $0.1936^{* *}$ \\
\hline Japan & 0.0382 & 0.0292 & -0.0620 \\
\hline Netherlands & -0.0745 & -0.0265 & -0.0279 \\
\hline Norway & -0.0162 & 0.0033 & -0.0125 \\
\hline Portugal & $0.1844^{* * *}$ & $0.1971^{* * *}$ & $0.1582^{* * *}$ \\
\hline Spain & 0.0586 & $0.1521^{* * *}$ & $0.1939^{* * *}$ \\
\hline Sweden & 0.0235 & 0.0701 & $0.3620^{* * *}$ \\
\hline Switzerland & $0.1061^{*}$ & $0.1608^{*}$ & $0.3052^{* * *}$ \\
\hline U.K. & 0.0775 & -0.0197 & 0.0716 \\
\hline Mean & 0.0274 & 0.0754 & 0.1316 \\
\hline Std. Dev. & 0.0824 & 0.1004 & 0.1413 \\
\hline Pooled Data & -0.0026 & $0.0665^{* * *}$ & $0.1145^{* * *}$ \\
\hline
\end{tabular}


Table 6

Correlation Structure and Stock Market Development

Reported are the panel regressions of the quarterly realized correlations $\left(Q R C\right.$ orr $\left._{i t}\right)$ between foreign stock market excess returns and exchange rate returns on two alternative measures of stock market development and fixed time effects $D_{t}$ for each quarter of the sample period 1990-2002:

$$
\begin{array}{lll}
\text { I: } & \text { QRCorr }_{i t}=\alpha+\beta \times \log \left(\text { MCap }_{i t} / G D P_{i t}\right) & +\gamma D_{t}+\epsilon_{i t} \\
\text { II: } & Q R \operatorname{Corr}_{i t}=\alpha+\beta \times \log \left(\text { TVol }_{i t} / G D P_{i t}\right) & +\gamma D_{t}+\epsilon_{i t}
\end{array}
$$

Quarterly realized correlations are calculated based on daily equity market excess returns for 17 OECD countries $(i=1,2, \ldots 17)$ relative to the U.S. equity market return and daily exchange rate returns of the respective dollar exchange rate. Market development is alternatively measured by the ratio of quarterly capital market capitalization $\left(M C a p_{i t}\right)$ to GDP or the ratio of quarterly cross border equity trading volume with the U.S. (TVol $i t)$ to GDP. We report in parenthesis robust standard errors (Newey-West) and allow for first order serial

\begin{tabular}{|c|c|c|c|c|c|}
\hline \multirow[b]{2}{*}{ Specification } & \multicolumn{4}{|c|}{ Coefficients $(n=724)$} & \multirow[b]{2}{*}{$\operatorname{Adj} \mathrm{R}^{2}$} \\
\hline & $\alpha$ & & $\beta$ & & \\
\hline I: & -0.0080 & $(0.0384)$ & $-0.0715^{* * *}$ & $(0.0231)$ & 0.292 \\
\hline II: & $0.1046^{* * *}$ & $(0.0403)$ & $-0.0199^{* * *}$ & $(0.0051)$ & 0.295 \\
\hline
\end{tabular}
autocorrelation of the error. Fixed effects are not reported. 


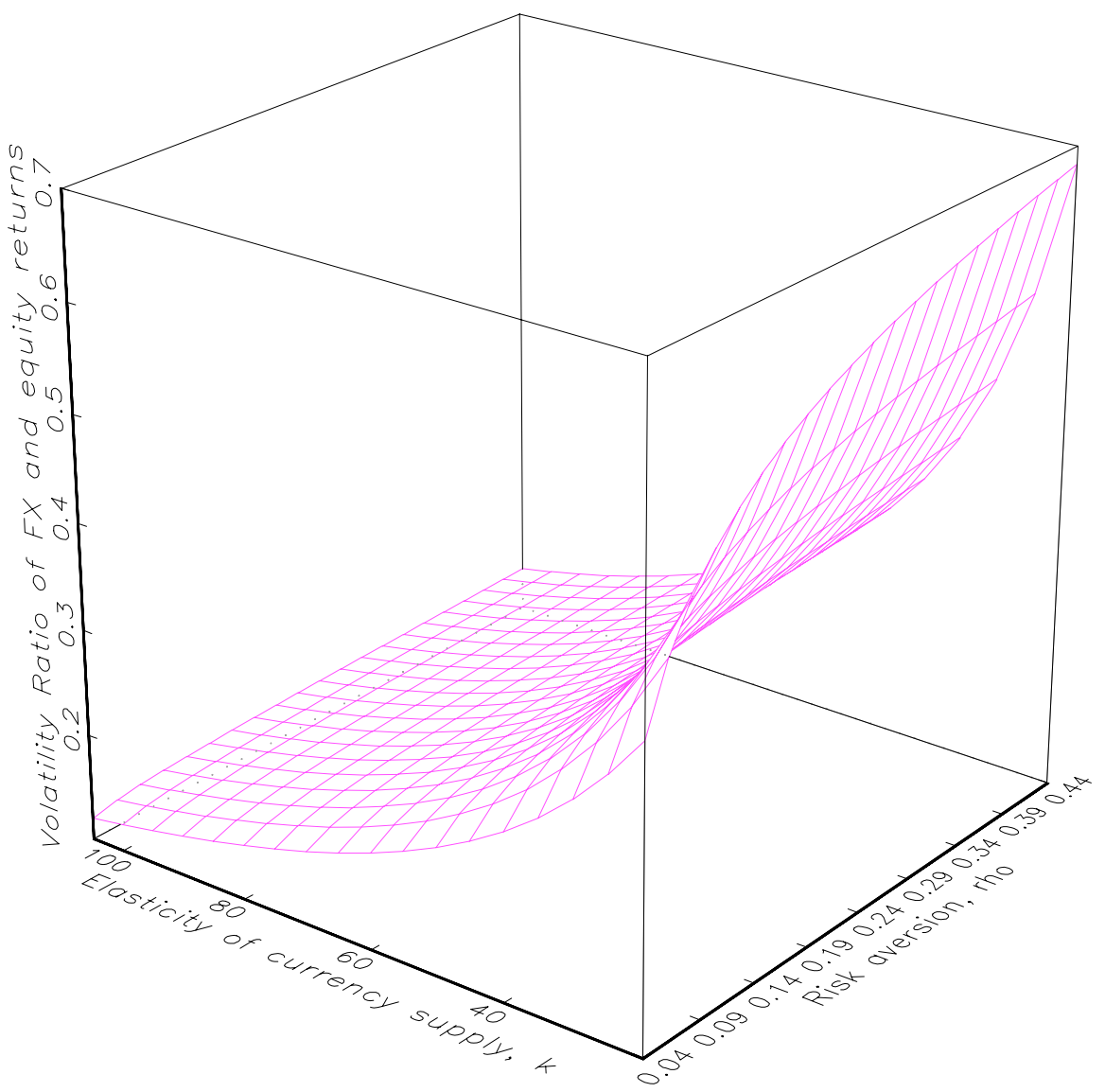

Figure 1: The equity returns is plotted for investor risk aversion parameters 0.04 to 0.44 and an elasticity of forex liquidity supply ranging from 20 to 100 . The riskless rate is $r=0.05$ and the parameters of the dividend process are $\bar{D}=1, \alpha_{D}=.25$ and $\sigma_{D}=0.1$. 


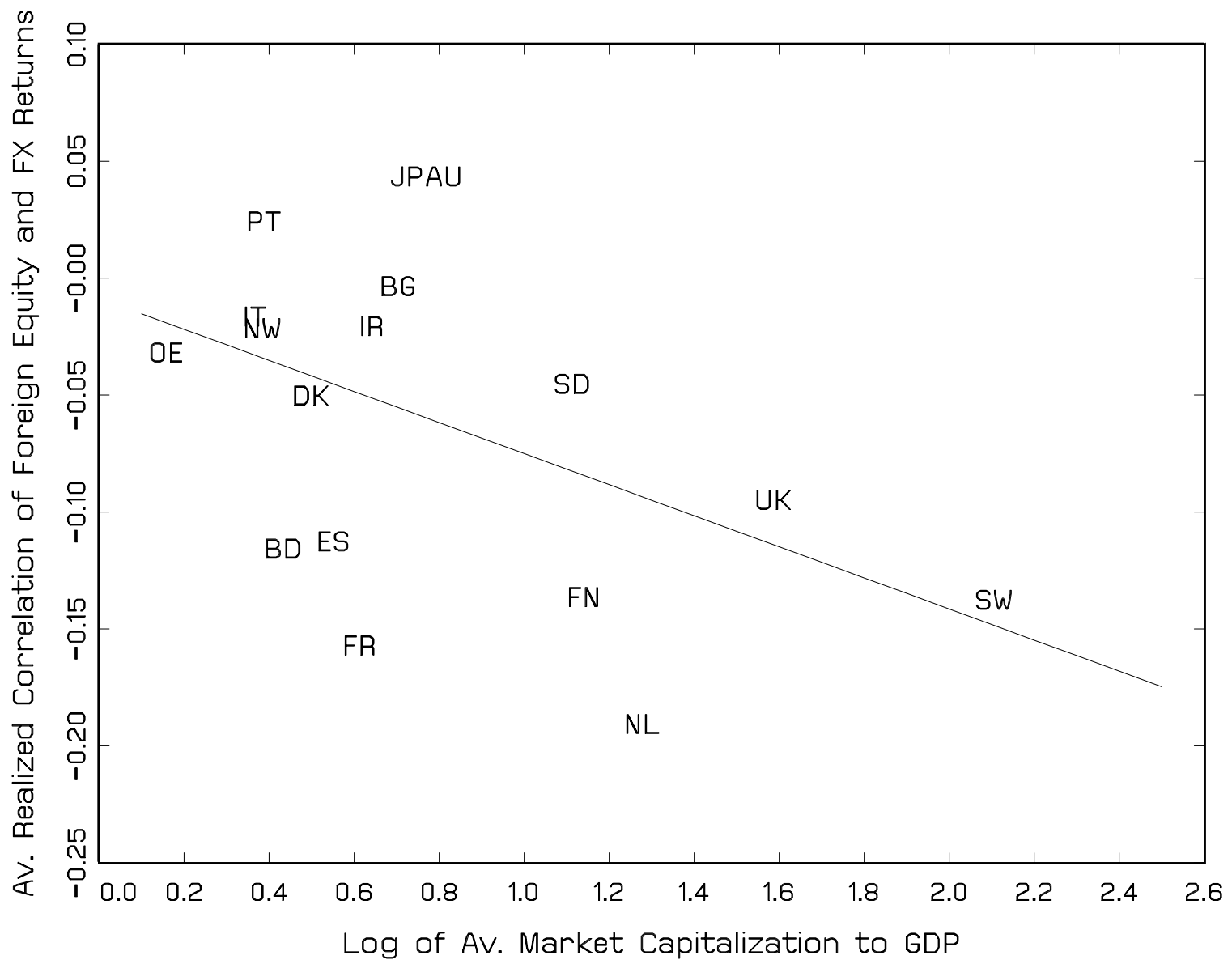

Figure 2: Plotted are the average monthly realized correlation of excess equity returns (defined as local index returns over U.S. index returns) and the corresponding foreign exchange return (in dollar terms) as a funtion of the log average market capitalization to GDP ratio for 17 OECD countries over the period 1995-2001. 